\title{
The Proteome Profiles of the Cerebellum of Juvenile, Adult and Aged Rats-An Ontogenetic Study
}

\author{
Michael Wille 1, Antje Schümann ${ }^{1}$, Andreas Wree ${ }^{1}$, Michael Kreutzer ${ }^{2}$, Michael O. Glocker ${ }^{2}$, \\ Grit Mutzbauer ${ }^{3}$ and Oliver Schmitt ${ }^{1, *}$
}

1 Department of Anatomy, Gertrudenstr. 9, 18055 Rostock, Germany; E-Mails: michael.wille@uni-rostock.de (M.W.); antje.schuemann@uni-rostock.de (A.S.); andreas.wree@med.uni-rostock.de (A.W.)

2 Proteome Center Rostock, Schillingallee 69, 18055 Rostock, Germany;

E-Mails: michael.kreutzer@med.uni-rostock.de (M.K.); michael.glocker@med.uni-rostock.de (M.O.G.)

3 Department of Pathology, Josef-Schneider-Str. 2, 97080 Würzburg, Germany; E-Mail: grit.lessner@uni-wuerzburg.de

* Author to whom correspondence should be addressed; E-Mail: schmitt@med.uni-rostock.de; Tel.: +49-(0)381-494-8408.

Academic Editor: Lee A. Bulla

Received: 12 June 2015 / Accepted: 25 August 2015 / Published: 7 September 2015

\begin{abstract}
In this study, we searched for proteins that change their expression in the cerebellum $(\mathrm{Ce})$ of rats during ontogenesis. This study focuses on the question of whether specific proteins exist which are differentially expressed with regard to postnatal stages of development. A better characterization of the microenvironment and its development may result from these study findings. A differential two-dimensional polyacrylamide gel electrophoresis (2DE) and matrix-assisted laser desorption/ionization time-of-flight mass spectrometry (MALDI-TOF-MS) analysis of the samples revealed that the number of proteins of the functional classes differed depending on the developmental stages. Especially members of the functional classes of biosynthesis, regulatory proteins, chaperones and structural proteins show the highest differential expression within the analyzed stages of development. Therefore, members of these functional protein groups seem to be involved in the development and differentiation of the Ce within the analyzed development stages. In this study, changes in the expression of proteins in the $\mathrm{Ce}$ at different postnatal developmental stages (postnatal days (P) 7, 90, and 637) could be observed. At the same time,
\end{abstract}


an identification of proteins which are involved in cell migration and differentiation was possible. Especially proteins involved in processes of the biosynthesis and regulation, the dynamic organization of the cytoskeleton as well as chaperones showed a high amount of differentially expressed proteins between the analyzed dates.

Keywords: proteomics; rat; brain; cerebellum; development

\section{Introduction}

The aim of this study was to analyze the differential proteome of the rat $\mathrm{Ce}$ at different developmental stages (7-day-old juvenile rats (P7), 90-day-old adult rats (P90) and 637-day-old aged rats (P637)).

The $\mathrm{Ce}$ is located in the hindbrain region and stems from the dorsolateral part of the alar plate. It develops from the rostral limbs at the level of the rhombencephalon. It is responsible for balance and posture as well as the coordination of gait, voluntary movement and is important in control of gaze [1]. Regarding the ontogenesis of the $\mathrm{Ce}$, additional information about the detailed development of this brain region, including changes of the brains mass, neuronal development and morphological changes is listed in the supplements (see Figure S1, accompanying text).

As mentioned above, the Ce is essential for different tasks in fine coordination and other important motor functions. Also in Parkinson's disease, a chronic progressive neurodegenerative disorder characterized by resting tremor, slowness of movements, rigidity, gait disturbance and postural instability [2], involvement of Ce in producing some motoric symptoms can be observed [3,4]. For example, different studies identified reciprocal connections between the basal ganglia and the Ce. Also functional and morphological changes in the Ce were detected related to akinesia, rigidity, tremor, gait disturbance, dyskinesia and some non-motor symptoms. Besides, pathological changes in the Ce might be induced by dopaminergic degeneration [2]. These findings provide a basis to explain the role of the Ce in Parkinson's disease. Based on this, an experimental investigation for optimized therapeutic strategies, e.g., stem cell transplantation in experimental models of Parkinson's disease, is still essential [5]. Previous studies [6,7] showed a different development of transplanted progenitor cells in neural and glial cell types of the neonatal and adult striata. A better characterization of the development of the microenvironment at the proteome level, including the determination of factors which are important for the development of this region, may support a better understanding of survival and differentiation of transplanted progenitor cells.

The lysosomal storage disease Niemann-Pick disease, type C1 (NPC1) is caused by a mutation of the NPC1 gene and results in a neurological disorder that is specifically related to the cerebellum. This neurodegenerative disorder leads to a huge loss of Purkinje neurons for which there is no definitive therapy yet. Main differences in the expression of proteins related to this disorder were found in the category of proteins involved in glucose metabolism, detoxification/oxidative stress and Alzheimer disease-related proteins. Furthermore, members of the fatty acid binding protein family, including FABP3, FABP5 and FABP7, show an altered expression in the NPC1 cerebellum [8]. Further aspects of the developing $\mathrm{Ce}$ are different changes of expression in the granular cell cytoskeleton. The neuronal cytoskeleton is composed of three main elements: micro- and neurofilaments as well as microtubules [9-11]. For the microfilaments, these polymers consist of actin with associated 
actin-regulatory proteins $[12,13]$. Neurofilaments consist of three polypeptides (NFH, NFM, NFL) and microtubules are polymers formed from dimers of $\alpha$ - and $\beta$-tubulin with associated proteins (microtubule-associated proteins (MAPS)). These proteins play a major role in the transport of new components down axons and dendrites and are important in cell division, cell migration and the formation of the complex morphology of neurons in the developing brain [14,15]. Hence, proteins associated with neurofilaments are involved in granule cell development and appearance of the characteristic morphology of mature granule cells. They must be involved in complex regulation of the composition and interactions between the components of the granule cell cytoskeleton [16].

In addition, expression and activity changes of glycolytic enzymes, proteins integrated in their biogenesis and metabolic components of the energy metabolism present another main aspect during growth and development of the rat brain. As an example, the activity of phospho-fructokinase (a key enzyme which catalyzes the conversion of fructose-6-phosphate to fructose-1,6-bisphosphate and which also represents the rate-limiting step in the glycolysis) is detectable in fetal brains at the twelfth day of gestation. It shows little change in enzyme activity in the brain from 5 days before birth to 8 days after birth. During this period, activity was $30 \%-40 \%$ of the normal value found in an adult brain. After 12 days, a rapid increase in activity to 21 days occurred [17]. Furthermore, the activities of additional glycolytic enzymes (hexokinase [18], aldolase [19], lactate-dehydrogenase [20], for example) do show substantial increases during maturation of the rat brain. As Leong and Clark stated [21], because of the correlation between the developmental sequences of glycolytic enzymes with the neurophylogenetic development of the brain, this adds support to the hypothesis that the development of the potential for glycolysis in the brain is a necessary prerequisite for the development of neurological competence.

In this study, proteins from the Ce of juvenile (P7) adult (P90) and aged rats (P637) were separated by 2DE and identified by MALDI-TOF-MS. An identification of differential protein expression changes during ontogenesis will be presented. As yet, protein expressions in the developing proteome are not fully understood and have not been published elsewhere.

\section{Results}

An identification of the differential protein expression between the groups of different ages (P7, P90 and P637) was accomplished by using 2DE with subsequent gel-matching, spot-warping and differential spot analysis combined with protein identification by MALDI-TOF-MS.

Figure 1 presents the images of the reference gels for the different development stages ((a) P7, (b) P90 and (c) P637). The spot compositions turn out to be comparable. An amount of $901( \pm 73)$ spots was detected in the six gels of P7, $637( \pm 108)$ spots in the six gels of P90 and $775( \pm 145)$ spots in the six gels of P637. 


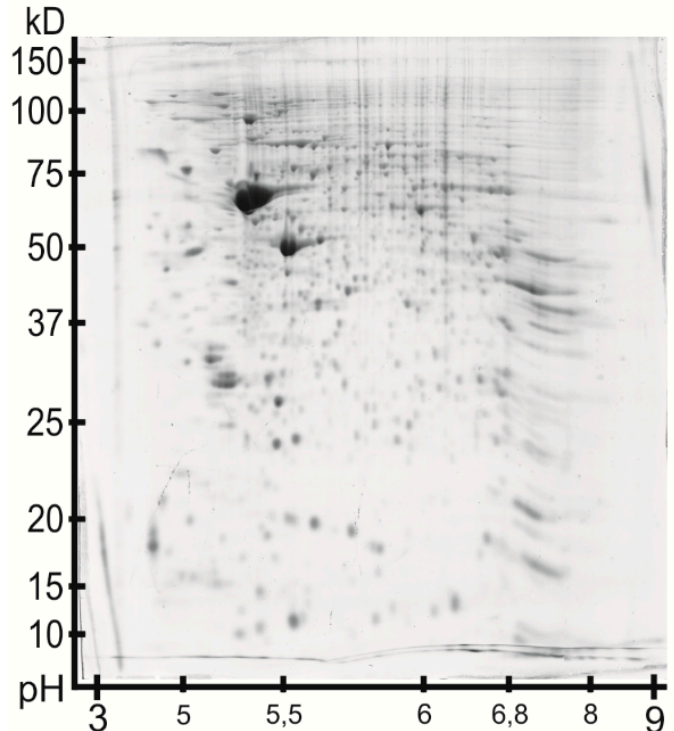

a

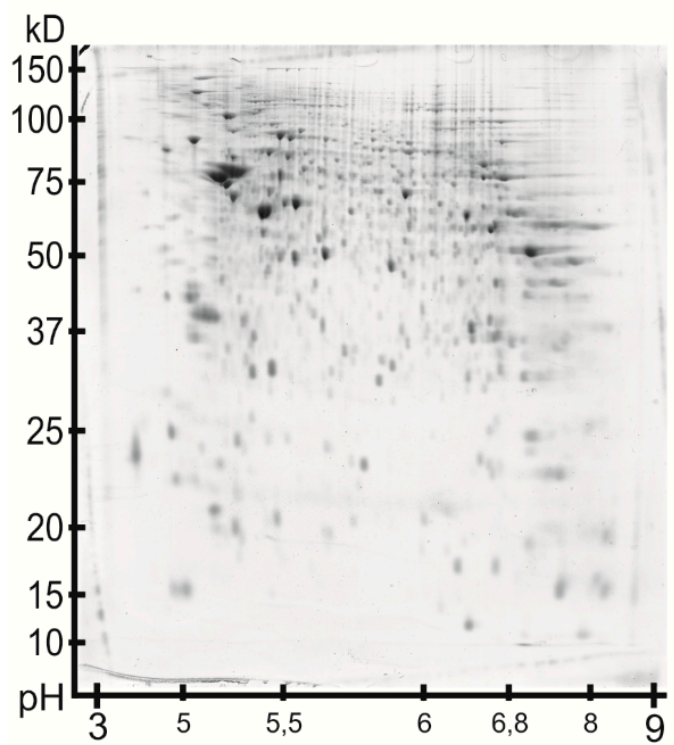

C

Figure 1. Overview of the reference gel images from the Ce. The Coomassie blue stainings of the gels have similar intensities. The 2DE-gel image of a P7 animal is shown in (a); In (b) the 2DE-gel image of a P90 animal is presented; (c) Shows the 2DE-gel image of an old P637 rat.

To obtain an impression of the quality of our manual segmentation of each spot in the Ce gels, a segmented gel image in combination with the 3D-visualization tool of Progenesis PG200 is presented (Figure 2).

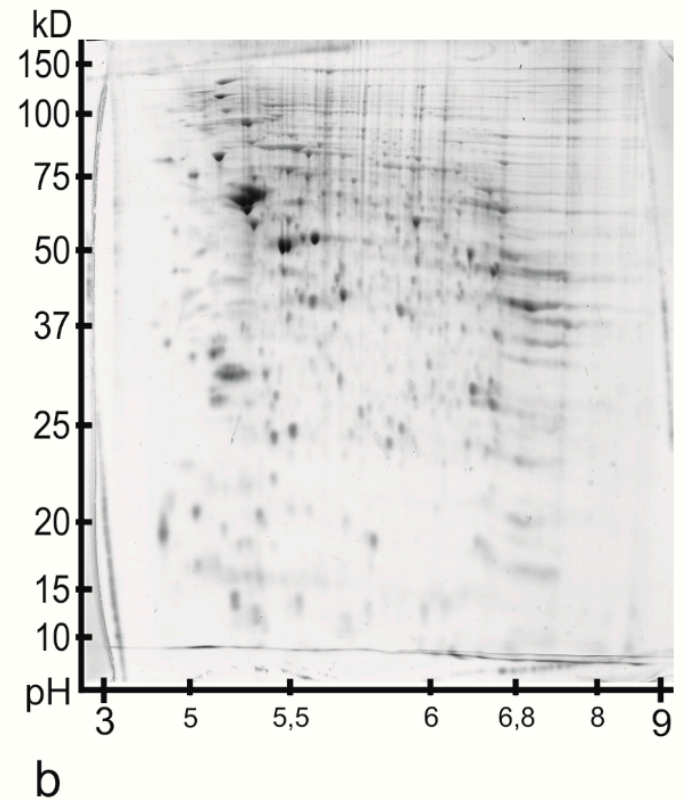

b

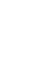




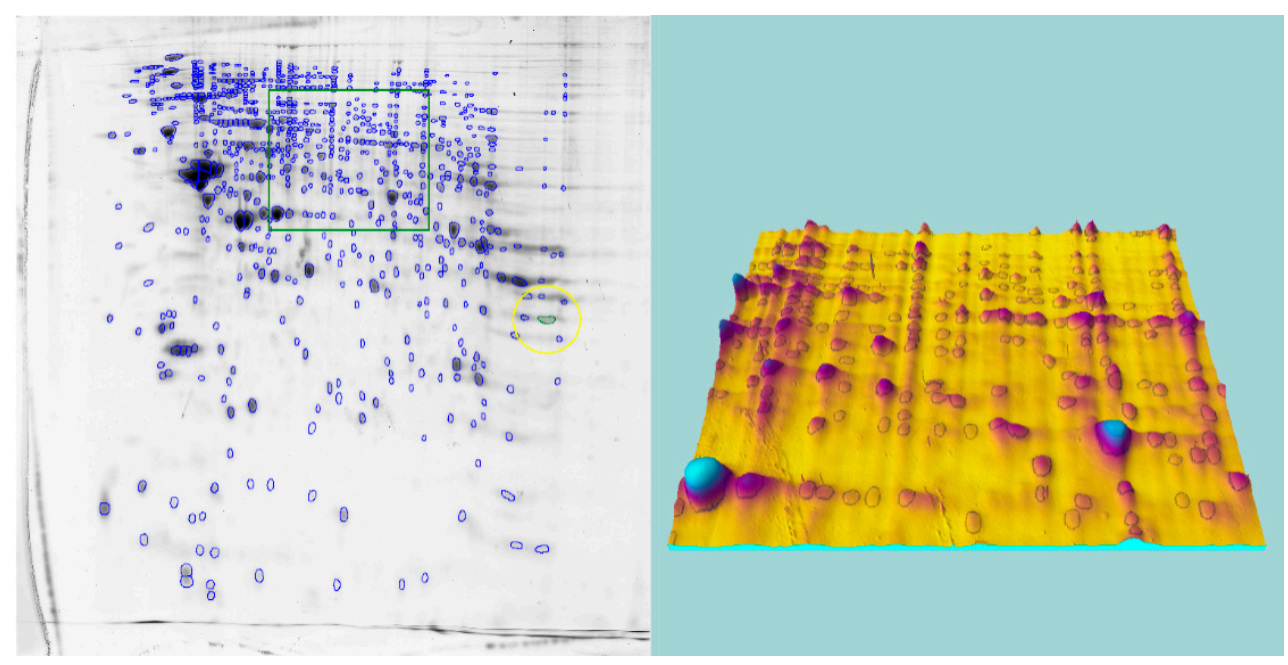

Figure 2. In order to perform an accurate segmentation of spots, the manual editing of spots was augmented by a 3D-visualization. This procedure has been applied to all reference gels as well as to all template gels. An example of the latter is presented here. The green box on the left indicates a region which is visualized as a 3D-view on the right side. The yellow circle is a temporary marker of the PG200.

The proteins which showed a differential expression were divided into 13 functional groups. In the following, a description of the groups of proteins is given which showed a higher amount of differential expression than the others. The description of the remaining analyzed proteins of the other functional groups is listed in the supplements. The differentially expressed proteins were divided into 13 functional groups. In the following, a description of the groups of proteins is given which showed a higher amount of differential expression than the others. The description of the remaining analyzed proteins of the other functional groups is listed in the supplements.

In the following, a detailed presentation of the up- and down-regulation of single proteins of categories which showed the most differential expression changes, setting P90 as base-line expression (see Figures 3B and 4B) is given. Based on the masspectrometic analysis, in the following, proteins which show an unambiguous differential expression are described in detail (see Table 1). The results of the multi condition coverage method as well as the Mann-Whitney $U$-test are presented. Proteins which were detected in different spots or which expression change is not distinct are marked with an (*) within the text. All analyzed proteins, identified by peptide mass fingerprinting, are arranged by their function and presented in Table S1. 
Table 1. Proteins identified by peptide mass fingerprinting in spots from Coomassie-stained gels arranged by their function. Accession: Accession number from UniProtKB/Swiss-Prot; Entry name: Entry name from UniProtKB/Swiss-Prot; Gene name: from UniProtKB/Swiss-Prot; Regulation (P7)/Regulation (P637): Differential expression in comparison to P90; Control/PD: Spot volume quotient; H: Number of differential expressed spots per biological replicate; Score: Mascot MOWSE-score; Qm: Number of mass values (tryptic peptides) assigned to the identified protein; MW: Theoretical molecular mass (Da); pI: Theoretical pI value taken from the Mascot report. The full description for the cellular location is listed in the list of abbreviations.

\begin{tabular}{|c|c|c|c|c|c|c|c|c|c|c|c|c|c|c|}
\hline \multirow{2}{*}{ Accession } & \multirow{2}{*}{ Entry Name } & \multirow{2}{*}{$\begin{array}{l}\text { Gene } \\
\text { Name }\end{array}$} & \multirow{2}{*}{$\begin{array}{l}\text { Functional Group/ } \\
\text { Protein Names }\end{array}$} & \multirow{2}{*}{$\begin{array}{l}\text { Cell } \\
\text { Localization }\end{array}$} & \multicolumn{2}{|c|}{ Regulation (P7) } & \multicolumn{2}{|c|}{ Regulation (P637) } & \multirow{2}{*}{$\begin{array}{l}\text { Control/PD } \\
\text { (P90/P7, P637) } \\
\end{array}$} & \multirow[t]{2}{*}{$\mathbf{H}$} & \multirow[t]{2}{*}{ Score } & \multirow[t]{2}{*}{ Qm } & \multirow{2}{*}{$\begin{array}{l}M_{\mathrm{w}} \\
\text { (Calc.) }\end{array}$} & \multirow[t]{2}{*}{ pI } \\
\hline & & & & & $(\mathrm{SVQ} \leq \mathbf{0 . 6})$ & $p$-Value & $(\mathrm{SVQ} \geq 1.67)$ & $p$-Value & & & & & & \\
\hline & & & Carbohydrate Metabolism & & & & & & & & & & & \\
\hline P08461 & ODP2_RAT & Dlat & $\begin{array}{l}\text { Dihydrolipoyllysine-residue } \\
\text { acetyltransferase component of } \\
\text { pyruvate dehydrogenase } \\
\text { complex, mitochondrial }\end{array}$ & Mmt & - & - & up & 0.0062 & 0.32 & 5 & 241 & 28 & 67,637 & 8.76 \\
\hline P04764 & ENOA_RAT & Enol & Alpha-enolase & $\mathrm{Cp}, \mathrm{M}$ & down & 0.1745 & - & - & 1.90 & 5 & 107 & 12 & 47,440 & 6.16 \\
\hline P07323 & ENOG_RAT & Eno2 & Gamma-enolase & $\mathrm{Cp}, \mathrm{M}$ & down & 0.3367 & - & - & 2.22 & 6 & 272 & 32 & 47,510 & 5.03 \\
\hline P04797 & G3P_RAT & Gapdh & $\begin{array}{l}\text { Glyceraldehyde-3-phosphate } \\
\text { dehydrogenase }\end{array}$ & $\mathrm{Cp}, \mathrm{Nc}$ & down & 0.0250 & - & - & 3.09 & 6 & 262 & 34 & 36,090 & 8.14 \\
\hline P04636 & MDHM_RAT & $M d h 2$ & $\begin{array}{l}\text { Malate dehydrogenase, } \\
\text { mitochondrial }\end{array}$ & Mmt & - & - & up & 0.1441 & 0.49 & 5 & 242 & 24 & 36,117 & 8.93 \\
\hline Q5XI78 & ODO1_RAT & $O g d h$ & $\begin{array}{l}\text { 2-oxoglutarate dehydrogenase, } \\
\text { mitochondrial }\end{array}$ & Mmt & down & 0.0190 & - & - & 1.93 & 4 & 158 & 18 & 117,419 & 6.3 \\
\hline P49432 & ODPB_RAT & $P d h b$ & $\begin{array}{l}\text { Pyruvate dehydrogenase E1 } \\
\text { component subunit beta, } \\
\text { mitochondrial }\end{array}$ & Mmt & down & 0.0039 & - & - & 5.80 & 6 & 139 & 18 & 39,299 & 6.2 \\
\hline D3Z955 & D3Z955_RAT & Pgm2ll & Phosphoglucomutase 2-like 1 & Cts & up & 0.0250 & - & - & 0.52 & 6 & 126 & 17 & 71,102 & 6.09 \\
\hline \multirow[t]{2}{*}{ P50137 } & TKT_RAT & $T k t$ & Transketolase & $\mathrm{Nc}$ & down & 0.0065 & - & - & 2.09 & 6 & 339 & 35 & 68,342 & 7.23 \\
\hline & & & Amino Acid Metabolism & & & & & & & & & & & \\
\hline Q6Q0N1 & CNDP2_RAT & Cndp2 & $\begin{array}{l}\text { Cytosolic non-specific } \\
\text { dipeptidase }\end{array}$ & $\mathrm{Cp}$ & - & - & up & 0.0106 & 0.48 & 5 & 205 & 29 & 53,116 & 5.43 \\
\hline
\end{tabular}


Table 1. Cont.

\begin{tabular}{|c|c|c|c|c|c|c|c|c|c|c|c|c|c|c|}
\hline \multirow{2}{*}{ Accession } & \multirow{2}{*}{ Entry Name } & \multirow{2}{*}{$\begin{array}{l}\text { Gene } \\
\text { Name }\end{array}$} & \multirow{2}{*}{$\begin{array}{l}\text { Functional Group/ } \\
\text { Protein Names }\end{array}$} & \multirow{2}{*}{$\begin{array}{l}\text { Cell } \\
\text { Localization }\end{array}$} & \multicolumn{2}{|c|}{ Regulation (P7) } & \multicolumn{2}{|c|}{ Regulation (P637) } & \multirow{2}{*}{$\begin{array}{l}\text { Control/PD } \\
\text { (P90/P7, P637) } \\
\end{array}$} & \multirow[t]{2}{*}{$\mathbf{H}$} & \multirow[t]{2}{*}{ Score } & \multirow[t]{2}{*}{ Qm } & \multirow{2}{*}{$\begin{array}{l}M_{\mathrm{w}} \\
\text { (Calc.) }\end{array}$} & \multirow[t]{2}{*}{ pI } \\
\hline & & & & & $(\mathrm{SVQ} \leq \mathbf{0 . 6})$ & $p$-Value & $(S V Q \geq 1.67)$ & $p$-Value & & & & & & \\
\hline & & & Amino Acid Metabolism & & & & & & & & & & & \\
\hline Q4V7C6 & GUAA_RAT & Gmps & $\begin{array}{l}\text { GMP synthase } \\
\text { (glutamine-hydrolyzing) }\end{array}$ & $\mathrm{Cp}$ & up & 0.0062 & - & - & 0.52 & 5 & 130 & 17 & 77,507 & 6.21 \\
\hline \multirow[t]{2}{*}{ P14882 } & PCCA_RAT & Pcca & $\begin{array}{l}\text { Propionyl-CoA carboxylase alpha } \\
\text { chain, mitochondrial }\end{array}$ & Mmt & down & 0.0283 & - & - & 2.14 & 5 & 262 & 32 & 82,198 & 7.59 \\
\hline & & & Fat Metabolism & & & & & & & & & & & \\
\hline Q5XI22 & THIC_RAT & Acat2 & $\begin{array}{l}\text { Acetyl-CoA acetyltransferase, } \\
\text { cytosolic }\end{array}$ & $\mathrm{Cp}$ & - & - & up & 0.0209 & 0.42 & 4 & 180 & 16 & 41,538 & 6.86 \\
\hline $\mathrm{O} 35263$ & PA1B3_RAT & Pafahlb3 & $\begin{array}{l}\text { Platelet-activating factor } \\
\text { acetylhydrolase IB subunit gamma }\end{array}$ & $\mathrm{Cp}$ & up & 0.0062 & - & - & 0.27 & 6 & 135 & 11 & 25,961 & 6.42 \\
\hline \multirow[t]{2}{*}{ Q568Z9 } & PHYIP_RAT & Phyhip & $\begin{array}{l}\text { Phytanoyl-CoA hydroxylase- } \\
\text { interacting protein }\end{array}$ & Pers & up & 0.0105 & - & - & 0.54 & 4 & 160 & 17 & 38,101 & 6.53 \\
\hline & & & Energy Metabolism & & & & & & & & & & & \\
\hline P15999 & ATPA_RAT & Atp5al & $\begin{array}{l}\text { ATP synthase subunit alpha, } \\
\text { mitochondrial }\end{array}$ & Mim, M & down & 0.0285 & up & 0.0001 & 3.49 & 5 & 295 & 38 & 59,831 & 9.22 \\
\hline P31399 & ATP5H_RAT & Atp $5 h$ & $\begin{array}{l}\text { ATP synthase subunit } \mathrm{d} \\
\text { mitochondrial }\end{array}$ & Mito, Mm & down & 0.0039 & - & - & 2.70 & 6 & 148 & 13 & 18,809 & 6.17 \\
\hline & & & NADH dehydrogenase (ubiquinone) & & & & & & & & & & & \\
\hline Q561S0 & NDUAA_RAT & Ndufa10 & $\begin{array}{l}1 \text { alpha subcomplex subunit } 10 \text {, } \\
\text { mitochondrial }\end{array}$ & Mmt & down & 0.0190 & - & - & 3.09 & 4 & 261 & 21 & 40,753 & 7.64 \\
\hline Q641Y2 & NDUS2_RAT & $N d u f s 2$ & $\begin{array}{l}\text { NADH dehydrogenase [ubiquinone] } \\
\text { iron-sulfur protein } 2 \text {, mitochondrial }\end{array}$ & Mim & down & 0.0163 & - & - & 2.46 & 6 & 247 & 31 & 52,927 & 6.52 \\
\hline D3ZG43 & D3ZG43_RAT & $N d u f_{s} 3$ & $\begin{array}{l}\text { NADH dehydrogenase } \\
\text { (Ubiquinone) Fe-S protein } 3 \\
\text { (Predicted), isoform CRA_c }\end{array}$ & Mito, Mm & down & 0.0039 & - & - & 3.29 & 6 & 280 & 21 & 20,190 & 6.32 \\
\hline P19234 & NDUV2_RAT & $N d u f v 2$ & $\begin{array}{l}\text { NADH dehydrogenase (ubiquinone) } \\
\text { flavoprotein } 2 \text {, mitochondrial }\end{array}$ & Mim & down & 0.0472 & - & - & 2.48 & 5 & 138 & 13 & 27,703 & 6.23 \\
\hline
\end{tabular}


Table 1. Cont.

\begin{tabular}{|c|c|c|c|c|c|c|c|c|c|c|c|c|c|c|}
\hline \multirow{2}{*}{ Accession } & \multirow{2}{*}{ Entry Name } & \multirow{2}{*}{$\begin{array}{l}\text { Gene } \\
\text { Name }\end{array}$} & \multirow{2}{*}{$\begin{array}{l}\text { Functional Group/ } \\
\text { Protein Names }\end{array}$} & \multirow{2}{*}{$\begin{array}{l}\text { Cell } \\
\text { Localization } \\
\end{array}$} & \multicolumn{2}{|c|}{ Regulation (P7) } & \multicolumn{2}{|c|}{ Regulation (P637) } & \multirow{2}{*}{$\begin{array}{l}\text { Control/PD } \\
\text { (P90/P7, P637) } \\
\end{array}$} & \multirow[t]{2}{*}{$\mathbf{H}$} & \multirow[t]{2}{*}{ Score } & \multirow[t]{2}{*}{ Qm } & \multirow{2}{*}{$\begin{array}{l}M_{\mathrm{W}} \\
\text { (Calc.) }\end{array}$} & \multirow[t]{2}{*}{ pI } \\
\hline & & & & & $(\mathrm{SVQ} \leq 0.6)$ & $p$-Value & $(S V Q \geq 1.67)$ & $p$-Value & & & & & & \\
\hline & & & Energy Metabolism & & & & & & & & & & & \\
\hline \multirow[t]{2}{*}{ P19234 } & NDUV2_RAT & $N d u f v 2$ & $\begin{array}{l}\text { NADH dehydrogenase } \\
\text { [ubiquinone] flavoprotein } 2 \text {, } \\
\text { mitochondrial }\end{array}$ & Mim & down & 0.0472 & - & - & 2.48 & 5 & 138 & 13 & 27,703 & 6.23 \\
\hline & & & Degratory Proteins & & & & & & & & & & & \\
\hline P60901 & PSA6_RAT & Psma6 & Proteasome subunit alpha type- 6 & $\mathrm{Cp}, \mathrm{Nc}$ & up & 0.0039 & - & - & 0.48 & 6 & 173 & 16 & 27,838 & 6.34 \\
\hline P40112 & PSB3_RAT & Psmb3 & Proteasome subunit beta type- 3 & $\mathrm{Cp}, \mathrm{Nc}$ & up & 0.0176 & - & - & 0.27 & 5 & 124 & 12 & 23,234 & 6.15 \\
\hline D4A640 & D4A640_RAT & Psmb4 & Proteasome subunit beta type & $\mathrm{Cp}, \mathrm{Nc}$ & up & 0.0065 & - & - & 0.56 & 6 & 102 & 7 & 25,858 & 5.97 \\
\hline Q9JHW0 & PSB7_RAT & Psmb7 & Proteasome subunit beta type- 7 & $\mathrm{Cp}, \mathrm{Nc}$ & up & 0.0039 & - & - & 0.44 & 6 & 120 & 10 & 30,250 & 8.13 \\
\hline \multirow[t]{2}{*}{ Q4V8E2 } & Q4V8E2_RAT & Psmd14 & $\begin{array}{l}\text { Proteasome (Prosome, macropain) } \\
\text { 26S subunit, non-ATPase, } 14\end{array}$ & $\mathrm{P}, \mathrm{Np}$ & up & 0.0881 & - & - & 0.56 & 4 & 64 & 7 & 34,726 & 6.06 \\
\hline & & & Antioxidants & & & & & & & & & & & \\
\hline O08557 & DDAH1_RAT & Ddahl & $\begin{array}{l}N(\mathrm{G}), N(\mathrm{G}) \text {-dimethylarginine } \\
\text { dimethylaminohydrolase } 1\end{array}$ & Mito, Cp & up & 0.0176 & - & - & 0.44 & 5 & 283 & 26 & 31,805 & 5.75 \\
\hline Q9Z1B2 & GSTM5_RAT & Gstm5 & Glutathione $S$-transferase $\mathrm{Mu} 5$ & $\mathrm{Cp}$ & down & 0.0065 & - & - & 2.92 & 6 & 232 & 22 & 27,067 & 6.33 \\
\hline Q9Z339 & GSTO1_RAT & Gstol & $\begin{array}{l}\text { Glutathione } S \text {-transferase } \\
\text { omega-1 }\end{array}$ & $\mathrm{Cp}, \mathrm{Cts}$ & down & 0.0547 & - & - & 2.27 & 6 & 81 & 10 & 27,936 & 6.25 \\
\hline Q9Z0V6 & PRDX3_RAT & $\operatorname{Prdx} 3$ & $\begin{array}{l}\text { Thioredoxin-dependent peroxide } \\
\text { reductase, mitochondrial }\end{array}$ & Mito & down & 0.0104 & - & - & 1.87 & 6 & 72 & 8 & 28,563 & 7.14 \\
\hline \multirow[t]{2}{*}{ O35244 } & PRDX6_RAT & $\operatorname{Prdx6}$ & Peroxiredoxin-6 & $\mathrm{Cp}$, Lyso & down & 0.0039 & - & - & 3.75 & 6 & 207 & 18 & 24,860 & 5.64 \\
\hline & & & Biosynthesis & & & & & & & & & & & \\
\hline Q6P7P5 & BZW1_RAT & $B z w 1$ & $\begin{array}{l}\text { Basic leucine zipper and W2 } \\
\text { domain-containing protein } 1\end{array}$ & $\mathrm{Cp}$ & up & 0.0550 & - & - & 0.52 & 4 & 77 & 10 & 48,184 & 5.75 \\
\hline Q4KM73 & KCY_RAT & Cmpkl & UMP-CMP kinase & $\mathrm{Nc}, \mathrm{Cp}$ & up & 0.0163 & - & - & 0.55 & 6 & 149 & 10 & 22,383 & 5.66 \\
\hline Q6P7P5 & BZW1_RAT & $B z w 1$ & $\begin{array}{l}\text { Basic leucine zipper and W2 } \\
\text { domain-containing protein } 1\end{array}$ & $\mathrm{Cp}$ & up & 0.0550 & - & - & 0.52 & 4 & 77 & 10 & 48,184 & 5.75 \\
\hline Q4KM73 & KCY_RAT & Cmpkl & UMP-CMP kinase & $\mathrm{Nc}, \mathrm{Cp}$ & up & 0.0163 & - & - & 0.55 & 6 & 149 & 10 & 22,383 & 5.66 \\
\hline
\end{tabular}


Table 1. Cont

\begin{tabular}{|c|c|c|c|c|c|c|c|c|c|c|c|c|c|c|}
\hline \multirow{2}{*}{ Accession } & \multirow{2}{*}{ Entry Name } & \multirow{2}{*}{$\begin{array}{l}\text { Gene } \\
\text { Name }\end{array}$} & \multirow{2}{*}{$\begin{array}{l}\text { Functional Group/ } \\
\text { Protein Names }\end{array}$} & \multirow{2}{*}{$\begin{array}{l}\text { Cell } \\
\text { Localization }\end{array}$} & \multicolumn{2}{|c|}{ Regulation (P7) } & \multicolumn{2}{|c|}{ Regulation (P637) } & \multirow{2}{*}{$\begin{array}{l}\text { Control/PD } \\
\text { (P90/P7, P637) } \\
\end{array}$} & \multirow[t]{2}{*}{$\mathbf{H}$} & \multirow[t]{2}{*}{ Score } & \multirow[t]{2}{*}{ Qm } & \multirow{2}{*}{$\begin{array}{l}M w \\
\text { (Calc.) }\end{array}$} & \multirow[t]{2}{*}{ pI } \\
\hline & & & & & $(\mathrm{SVQ} \leq \mathbf{0 . 6})$ & $p$-Value & $(\mathrm{SVQ} \geq 1.67)$ & $p$-Value & & & & & & \\
\hline & & & Biosynthesis & & & & & & & & & & & \\
\hline P62630 & EF1A1_RAT & Eeflal & Elongation factor 1-alpha 1 & $\mathrm{Cp}, \mathrm{Nc}$ & up & 0.5839 & - & - & 0.44 & 5 & 73 & 10 & 50,424 & 9.1 \\
\hline Q68FR6 & EF1G_RAT & Eeflg & Elongation factor 1-gamma & Rs, Cts & up & 0.0550 & - & - & 0.37 & 6 & 235 & 27 & 50,371 & 6.31 \\
\hline Q5RKI1 & IF4A2_RAT & Eif4a2 & Eukaryotic initiation factor 4A-II & Cts & - & - & down & 0.0090 & 5.16 & 5 & 196 & 28 & 46,601 & 5.33 \\
\hline Q32PX7 & FUBP1_RAT & Fubpl & $\begin{array}{l}\text { Far upstream element-binding } \\
\text { protein } 1\end{array}$ & $\mathrm{Nc}$ & down & 0.0283 & - & - & 1.78 & 5 & 97 & 10 & 67,326 & 7.18 \\
\hline Q794E4 & HNRPF_RAT & Hnrnpf & $\begin{array}{l}\text { Heterogeneous nuclear } \\
\text { ribonucleoprotein F }\end{array}$ & $\mathrm{Nc}, \mathrm{Np}$ & up & 0.0105 & - & - & 0.11 & 4 & 158 & 21 & 46,043 & 5.31 \\
\hline Q6AY09 & HNRH2_RAT & Hnrnph2 & $\begin{array}{l}\text { Heterogeneous nuclear } \\
\text { ribonucleoprotein } \mathrm{H} 2\end{array}$ & $\mathrm{Nc}, \mathrm{Np}$ & - & - & up & 0.0285 & 0.42 & 5 & 194 & 28 & 49,547 & 5.89 \\
\hline P85973 & PNPH_RAT & Pnp & $\begin{array}{l}\text { Purine nucleoside phosphorylase } \\
\text { Serine/threonine-protein }\end{array}$ & $\mathrm{Cp}$ & up & 0.0550 & - & - & 0.59 & 6 & 263 & 31 & 32,566 & 6.46 \\
\hline P62716 & PP2AB_RAT & $P p p 2 c b$ & $\begin{array}{l}\text { phosphatase } 2 \text { A catalytic subunit } \\
\text { beta isoform }\end{array}$ & $\mathrm{Cp}, \mathrm{Nc}, \mathrm{Cr}$ & - & - & down & 0.0143 & 2.41 & 4 & 169 & 16 & 36,123 & 5.21 \\
\hline P53042 & PPP5_RAT & Ppp5c & $\begin{array}{l}\text { Serine/threonine-protein } \\
\text { phosphatase } 5\end{array}$ & $\mathrm{Nc}$ & down & 0.0758 & - & - & 2.37 & 5 & 159 & 18 & 57,507 & 5.84 \\
\hline F1LPS8 & F1LPS8_RAT & Pura & $\begin{array}{l}\text { Transcriptional activator } \\
\text { protein Pur-alpha }\end{array}$ & $\mathrm{Nc}, \mathrm{Cp}$ & down & 0.1093 & down & 0.0176 & 1.70 & 6 & 73 & 12 & 34,976 & 6.07 \\
\hline Q925G0 & RBM3_RAT & $R b m 3$ & Putative RNA-binding protein 3 & $\mathrm{Nc}, \mathrm{Cp}$ & down & 0.0163 & - & - & 1.87 & 5 & 73 & 5 & 16,845 & 6.92 \\
\hline Q5XIG8 & STRAP_RAT & Strap & $\begin{array}{l}\text { Serine-threonine kinase } \\
\text { receptor-associated protein }\end{array}$ & $\mathrm{Cp}, \mathrm{Nc}$ & up & 0.0163 & up & 0.0163 & 0.38 & 6 & 141 & 15 & 38,717 & 4.99 \\
\hline Q4KM49 & SYYC_RAT & Yars & $\begin{array}{l}\text { Tyrosine - tRNA ligase, } \\
\text { cytoplasmic }\end{array}$ & $\mathrm{Cp}$ & up & 0.0285 & up & 0.0547 & 0.57 & 5 & 141 & 18 & 59,420 & 6.57 \\
\hline P62961 & YBOX1_RAT & $Y b x 1$ & $\begin{array}{l}\text { Nuclease-sensitive } \\
\text { element-binding protein } 1\end{array}$ & $\mathrm{Cp}, \mathrm{Nc}, \mathrm{Cpg}$ & up & 0.0446 & - & - & 0.52 & 5 & 219 & 16 & 35,709 & 9.87 \\
\hline
\end{tabular}


Table 1. Cont

\begin{tabular}{|c|c|c|c|c|c|c|c|c|c|c|c|c|c|c|}
\hline \multirow{2}{*}{ Accession } & \multirow{2}{*}{ Entry Name } & \multirow{2}{*}{$\begin{array}{l}\text { Gene } \\
\text { Name }\end{array}$} & \multirow{2}{*}{$\begin{array}{l}\text { Functional Group/ } \\
\text { Protein Names } \\
\end{array}$} & \multirow{2}{*}{$\begin{array}{l}\text { Cell } \\
\text { Localization }\end{array}$} & \multicolumn{2}{|c|}{ Regulation (P7) } & \multicolumn{2}{|c|}{ Regulation (P637) } & \multirow{2}{*}{$\begin{array}{l}\text { Control/PD } \\
\text { (P90/P7, P637) } \\
\end{array}$} & \multirow[t]{2}{*}{$\mathbf{H}$} & \multirow[t]{2}{*}{ Score } & \multirow[t]{2}{*}{ Qm } & \multirow{2}{*}{$\begin{array}{l}M_{\mathrm{w}} \\
\text { (Calc. })\end{array}$} & \multirow[t]{2}{*}{ pI } \\
\hline & & & & & $(\mathrm{SVQ} \leq 0.6)$ & $p$-Value & $(\mathrm{SVQ} \geq 1.67)$ & $p$-Value & & & & & & \\
\hline & & & Signal Transduction & & & & & & & & & & & \\
\hline P97697 & IMPA1_RAT & Impal & Inositol monophosphatase 1 & $\mathrm{Cp}$ & up & 0.3367 & - & - & 0.48 & 6 & 214 & 16 & 30,834 & 5.17 \\
\hline \multirow[t]{2}{*}{ P62260 } & 1433E_RAT & Ywhae & 14-3-3 protein epsilon & $\mathrm{Cp}, \mathrm{Mel}$ & up & 0.3367 & - & - & 0.51 & 6 & 213 & 34 & 29,326 & 4.63 \\
\hline & & & Regulation & & & & & & & & & & & \\
\hline Q64640 & ADK_RAT & $A d k$ & Adenosine kinase & Cts, Nc & down & 0.0039 & - & - & 4.50 & 6 & 129 & 13 & 40,450 & 5.72 \\
\hline Q02589 & ADPRH_RAT & Adprh & (Protein ADP-ribosylarginine) hydrolase & $\mathrm{Cp}$ & up & 0.0176 & - & - & 0.31 & 5 & 111 & 12 & 40,220 & 5.62 \\
\hline Q07936 & ANXA2_RAT & Anxa2 & Annexin A2 & $\mathrm{M}, \mathrm{Mel}$ & up & 0.0782 & - & - & 0.53 & 6 & 71 & 12 & 38,939 & 7.55 \\
\hline P27139 & CAH2_RAT & $\mathrm{Ca} 2$ & Carbonic anhydrase 2 & $\mathrm{Cp}$ & down & 0.0104 & - & - & 5.01 & 6 & 89 & 11 & 29,267 & 6.89 \\
\hline P45592 & COF1_RAT & $C f l 1$ & Cofilin-1 & $\mathrm{Nm}, \mathrm{Cp}$ & up & 0.1745 & - & - & 0.56 & 5 & 154 & 16 & 18,749 & 8.22 \\
\hline P08082 & CLCB_RAT & $C l t b$ & Clathrin light chain B & Cpv, M & down & 0.0209 & down & 0.0209 & 2.31 & 4 & 104 & 8 & 25,216 & 4.56 \\
\hline B0BNE5 & ESTD_RAT & Esd & $S$-formylglutathione hydrolase & $\mathrm{Cp}, \mathrm{Cpv}$ & down & 0.1003 & - & - & 1.86 & 5 & 181 & 15 & 31,971 & 6.44 \\
\hline P07936 & NEUM_RAT & Gap43 & Neuromodulin & M & up & 0.0039 & - & - & 0.11 & 6 & 95 & 7 & 23,703 & 4.61 \\
\hline P50399 & GDIB_RAT & Gdi2 & Rab GDP dissociation inhibitor beta & $\mathrm{Cp}, \mathrm{M}$ & up & 0.1093 & - & - & 0.52 & 6 & 311 & 38 & 51,018 & 5.93 \\
\hline Q63228 & GMFB_RAT & $G m f b$ & Glia maturation factor beta & $\mathrm{Cp}$ & up & 0.0039 & - & - & 0.13 & 6 & 78 & 6 & 16,897 & 5.32 \\
\hline P62749 & HPCL1_RAT & Hpcall & Hippocalcin-like protein 1 & Pem & down & 0.0374 & - & - & 1.96 & 6 & 202 & 17 & 22,438 & 5.32 \\
\hline O88767 & PARK7_RAT & Park7 & Protein DJ-1 & $\mathrm{Cp}, \mathrm{Nc}$, Mito & down & 0.1093 & - & - & 1.74 & 6 & 280 & 21 & 20,190 & 6.32 \\
\hline Q1RP74 & Q1RP74_RAT & $T b c b$ & Tubulin folding cofactor B & $\mathrm{Nc}, \mathrm{Cp}, \mathrm{MT}$ & up & 0.0176 & - & - & 0.32 & 5 & 196 & 17 & 27,515 & 4.93 \\
\hline P70566 & TMOD2_RAT & Tmod2 & Tropomodulin-2 & Cp, Csk & down & 0.0250 & - & - & 3.39 & 6 & 185 & 15 & 39,468 & 5.34 \\
\hline P63029 & TCTP_RAT & $T p t 1$ & Translationally-controlled tumor protein & $\mathrm{Cp}$ & up & 0.0106 & - & - & 0.29 & 5 & 135 & 10 & 19,564 & 4.76 \\
\hline P11232 & THIO_RAT & $T x n$ & Thioredoxin & $\mathrm{Nc}, \mathrm{Cp}, \mathrm{Sc}$ & up & 0.0039 & - & - & 0.24 & 6 & 67 & 4 & 12,008 & 4.8 \\
\hline Q920J4 & TXNL1_RAT & Txnl1 & Thioredoxin-like protein 1 & $\mathrm{Cp}$ & up & 0.0105 & - & - & 0.19 & 4 & 257 & 19 & 32,628 & 4.84 \\
\hline
\end{tabular}


Table 1. Cont.

\begin{tabular}{|c|c|c|c|c|c|c|c|c|c|c|c|c|c|c|}
\hline \multirow{2}{*}{ Accession } & \multirow{2}{*}{ Entry Name } & \multirow{2}{*}{$\begin{array}{l}\text { Gene } \\
\text { Name }\end{array}$} & \multirow{2}{*}{$\begin{array}{l}\text { Functional Group/ } \\
\text { Protein Names }\end{array}$} & \multirow{2}{*}{$\begin{array}{l}\text { Cell } \\
\text { Localization }\end{array}$} & \multicolumn{2}{|c|}{ Regulation (P7) } & \multicolumn{2}{|c|}{ Regulation (P637) } & \multirow{2}{*}{$\begin{array}{l}\text { Control/PD } \\
(\mathrm{P90} / \mathrm{P7}, \mathrm{P637}) \\
\end{array}$} & \multirow[t]{2}{*}{$\mathbf{H}$} & \multirow[t]{2}{*}{ Score } & \multirow[t]{2}{*}{ Qm } & \multirow{2}{*}{$\begin{array}{l}M_{\mathrm{w}} \\
\text { (Calc.) }\end{array}$} & \multirow[t]{2}{*}{ pI } \\
\hline & & & & & $(\mathrm{SVQ} \leq \mathbf{0 . 6})$ & $p$-Value & $(\mathrm{SVQ} \geq 1.67)$ & $p$-Value & & & & & & \\
\hline & & & Chaperones & & & & & & & & & & & \\
\hline Q6P502 & TCPG_RAT & Cct3 & T-complex protein 1 subunit gamma & $\mathrm{Cp}$ & - & - & up & 0.0062 & 0.33 & 5 & 210 & 31 & 61,179 & 6.23 \\
\hline Q68FQ0 & TCPE_RAT & Cct 5 & T-complex protein 1 subunit epsilon & $\mathrm{Cp}, \mathrm{Cts}$ & up & 0.0176 & up & 0.0330 & 0.31 & 5 & 329 & 43 & 59,955 & 5.51 \\
\hline P34058 & HS90B_RAT & Hsp90ab1 & Heat shock protein HSP 90-beta & $\mathrm{Cp}, \mathrm{Mel}$ & down & 0.2733 & down & 0.0104 & 2.39 & 6 & 260 & 42 & 83,571 & 4.97 \\
\hline P06761 & GRP78_RAT & Hspa5 & Heat shock $70 \mathrm{kDa}$ protein 5 & ER, Mel & down & 0.8728 & down & 0.0105 & 3.49 & 6 & 315 & 34 & 72,474 & 5.07 \\
\hline \multirow[t]{2}{*}{ P11598 } & PDIA3_RAT & Pdia 3 & Protein disulfide-isomerase A3 & ER, Mel & down & 1.0000 & down & 0.9168 & 1.79 & 5 & 73 & 8 & 57,044 & 5.88 \\
\hline & & & Structural Proteins & & & & & & & & & & & \\
\hline B2RYJ7 & B2RYJ7_RAT & Actrlb & $\begin{array}{l}\text { ARP1 actin-related protein } 1 \text { homolog B } \\
\text { (Yeast) }\end{array}$ & $\mathrm{Cp}, \mathrm{Csk}$ & down & 0.0782 & - & - & 1.77 & 6 & 173 & 18 & 42,369 & 5.98 \\
\hline Q4V7C7 & ARP3_RAT & Actr 3 & Actin-related protein 3 & Cp, Csk & up & 0.0163 & - & - & 0.52 & 6 & 230 & 27 & 47,783 & 5.61 \\
\hline B2GUZ5 & CAZA1_RAT & Capzal & F-actin-capping protein subunit alpha-1 & $\mathrm{Cp}, \mathrm{Csk}$ & up & 0.0250 & - & - & 0.57 & 6 & 230 & 19 & 33,060 & 5.43 \\
\hline Q5XI32 & CAPZB_RAT & $C a p z b$ & F-actin-capping protein subunit beta & $\mathrm{Cp}, \mathrm{Csk}$ & up & 0.0163 & - & - & 0.57 & 6 & 184 & 20 & 30,952 & 5.69 \\
\hline P47819 & GFAP_RAT & Gfap & Glial fibrillary acidic protein & $\mathrm{Cp}$ & down & 0.0039 & - & - & 5.72 & 6 & 381 & 48 & 49,984 & 5.35 \\
\hline D4A6B2 & D4A6B2_RAT & Immt & Mitochondrial inner membrane protein & Mito, Mim & down & 0.0547 & - & - & 2.58 & 6 & 375 & 46 & 83,104 & 5.34 \\
\hline P23565 & AINX_RAT & Ina & Alpha-internexin & $\mathrm{Nf}$ & down & 0.0547 & - & - & 1.92 & 6 & 391 & 45 & 56,253 & 5.2 \\
\hline P30009 & MARCS_RAT & Marcks & $\begin{array}{l}\text { Myristoylated alanine-rich } \\
\text { C-kinase substrate }\end{array}$ & $\mathrm{Cp}, \mathrm{M}, \mathrm{La}$ & up & 0.0065 & - & - & 0.40 & 6 & 109 & 9 & 29,834 & 4.32 \\
\hline P19527 & NFL_RAT & Nefl & Neurofilament light polypeptide & $\mathrm{Nf}, \mathrm{A}$ & down & 0.0039 & - & - & 3.49 & 6 & 412 & 53 & 61,355 & 4.63 \\
\hline P12839 & NFM_RAT & Nefm & Neurofilament medium polypeptide & Nf, Csk, A & down & 0.0090 & - & - & 2.84 & 5 & 291 & 48 & 95,848 & 4.77 \\
\hline B3GNI6 & SEP11_RAT & Sept11 & Septin-11 & $\mathrm{Cp}, \mathrm{A}$ & down & 0.0163 & down & 0.25059 & 1.87 & 5 & 69 & 11 & 50,005 & 6.24 \\
\hline P13668 & STMN1_RAT & Stmnl & Stathmin & $\mathrm{Cp}, \mathrm{Csk}$ & up & 0.3367 & - & - & 0.04 & 6 & 171 & 14 & 17,278 & 5.76 \\
\hline Q6AYZ1 & TBA1C_RAT & Tubalc & Tubulin alpha-1C chain & $\mathrm{Cp}, \mathrm{Csk}$ & down & 0.0190 & - & - & 3.73 & 4 & 87 & 8 & 50,590 & 4.96 \\
\hline Q3KRE8 & TBB2B_RAT & $T u b b 2 b$ & Tubulin beta-2B chain & $\mathrm{Cp}, \mathrm{Csk}$ & up & 0.3472 & - & - & 0.48 & 5 & 317 & 42 & 50,377 & 4.78 \\
\hline
\end{tabular}


Table 1. Cont.

\begin{tabular}{|c|c|c|c|c|c|c|c|c|c|c|c|c|c|c|}
\hline \multirow{2}{*}{ Accession } & \multirow{2}{*}{ Entry Name } & \multirow{2}{*}{$\begin{array}{l}\text { Gene } \\
\text { Name }\end{array}$} & \multirow{2}{*}{$\begin{array}{l}\text { Functional Group/ } \\
\text { Protein Names }\end{array}$} & \multirow{2}{*}{$\begin{array}{l}\text { Cell } \\
\text { Localization } \\
\end{array}$} & \multicolumn{2}{|c|}{ Regulation (P7) } & \multicolumn{2}{|c|}{ Regulation (P637) } & \multirow{2}{*}{$\begin{array}{l}\text { Control/PD } \\
(\mathrm{P90} / \mathrm{P7}, \mathrm{P637}) \\
\end{array}$} & \multirow[t]{2}{*}{$\mathbf{H}$} & \multirow[t]{2}{*}{ Score } & \multirow[t]{2}{*}{ Qm } & \multirow{2}{*}{$\begin{array}{l}M w \\
\text { (Calc. })\end{array}$} & \multirow[t]{2}{*}{ pI } \\
\hline & & & & & $(\mathrm{SVQ} \leq \mathbf{0 . 6})$ & $p$-Value & $(\mathrm{SVQ} \geq 1.67)$ & $p$-Value & & & & & & \\
\hline & & & Transport Proteins & & & & & & & & & & & \\
\hline Q5M7T6 & Q5M7T6_RAT & Atp6v0d1 & $\begin{array}{l}\text { ATPase, } \mathrm{H}+\text { transporting, lysosomal } \\
38 \mathrm{kDa}, \mathrm{V} 0 \text { subunit } \mathrm{d} 1\end{array}$ & M & up & 0.0039 & - & - & 0.23 & 5 & 111 & 11 & 40,731 & 4.89 \\
\hline Q811Q2 & CLIC6_RAT & Clic6 & Chloride intracellular channel protein 6 & $\mathrm{Cp}, \mathrm{M}$ & down & 0.0039 & down & 0.01902 & 2.43 & 6 & 204 & 19 & 64,990 & 4.29 \\
\hline Q6AYH5 & DCTN2_RAT & Dctn2 & Dynactin subunit 2 & $\mathrm{Cp}, \mathrm{M}$ & up & 0.0833 & - & - & 0.49 & 4 & 218 & 21 & 44,235 & 5.14 \\
\hline Q62871 & DC1I2_RAT & Dyncli2 & $\begin{array}{l}\text { Cytoplasmic dynein } 1 \text { intermediate } \\
\text { chain } 2\end{array}$ & Cp, Csk & down & 0.1003 & down & 0.06789 & 2.13 & 5 & 111 & 11 & 71,533 & 5.11 \\
\hline P55051 & FABP7_RAT & Fabp 7 & Fatty acid-binding protein, brain & $\mathrm{Cp}$ & up & 0.0039 & - & - & 0.21 & 6 & 152 & 12 & 15,140 & 5.46 \\
\hline Q9Z2L0 & VDAC1_RAT & $V d a c 1$ & $\begin{array}{l}\text { Voltage-dependent anion-selective } \\
\text { channel protein } 1\end{array}$ & Mom, M & down & 0.0500 & down & 0.52243 & 2.44 & 4 & 215 & 17 & 30,851 & 8.62 \\
\hline P81155 & VDAC2_RAT & $V d a c 2$ & $\begin{array}{l}\text { Voltage-dependent anion-selective } \\
\text { channel protein } 2\end{array}$ & Mom & down & 0.0039 & - & - & 2.25 & 6 & 168 & 15 & 32,353 & 7.44 \\
\hline
\end{tabular}


A

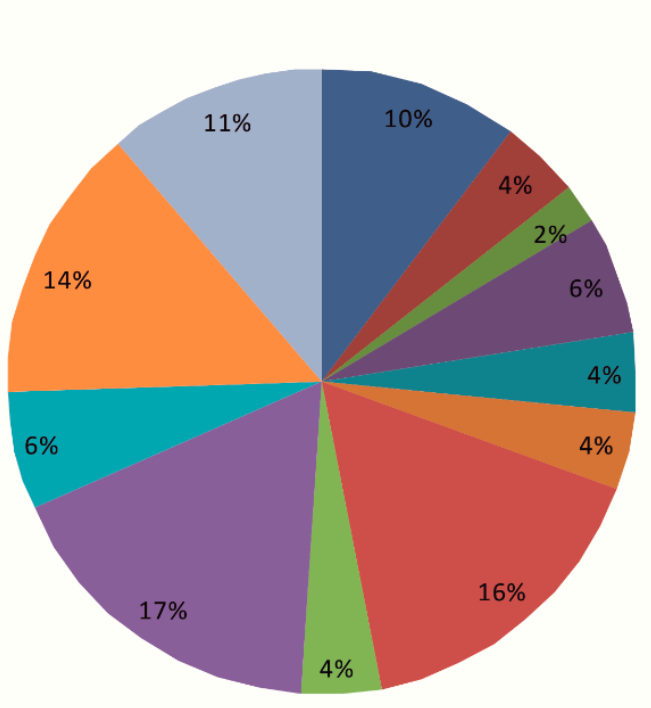

proteins carbohydrate metabolism (10\%)

proteins amino acid metabolism (4\%)

\#proteins fat metabolism (2\%)

- proteins energy metabolism (6\%)

aproteins degradation (4\%)

proteins antioxidants (4\%)

- proteins transmitter metabolism (0\%)

Droteins biosynthesis (16\%)

- proteins signal transduction (4\%)

Eproteins regulation (17\%)

chaperones $(6 \%)$

चstructural proteins (14\%)

transport proteins (11\%)

B

\begin{tabular}{|c|c|c|c|c|c|}
\hline & Amount of differentially & & & & \\
\hline Category & expressed proteins in total & up-regulated & down-regulated & absent in P7 & absent in P90 \\
\hline $\mathrm{pcm}$ & 14 & 4 & 10 & - & - \\
\hline paam & 6 & 1 & 4 & - & 1 \\
\hline pfm & 3 & 2 & 1 & - & - \\
\hline pem & 9 & - & 9 & - & - \\
\hline pd & 6 & 6 & - & - & - \\
\hline pa & 5 & 1 & 4 & - & - \\
\hline pb & 23 & 15 & 5 & - & 3 \\
\hline pst & 6 & 3 & 3 & - & - \\
\hline $\mathrm{pr}$ & 24 & 13 & 10 & - & 1 \\
\hline cp & 9 & 5 & 4 & - & - \\
\hline sp & 20 & 8 & 12 & - & - \\
\hline tp & 15 & 5 & 10 & - & - \\
\hline ptm & - & - & - & - & - \\
\hline
\end{tabular}

Figure 3. Differential expression of proteins in the Ce at P7. (A) Relative frequencies of proteins in the Ce that are differentially expressed (P7 vs. P90); (B) Number of differentially expressed proteins of different protein categories within the $\mathrm{Ce}$ (P7) vs. (P90). (Abbreviations for Figures $3 \mathrm{~B}$ and $4 \mathrm{~B}$, pcm: proteins carbohydrate metabolism, paam: proteins amino acid metabolism, pfm: proteins fat metabolism, pem: proteins energy metabolism, pd: proteins degradation, pa: proteins antioxidants, ptm: proteins transmitter metabolism, pb: proteins biosynthesis, pst: proteins signal transduction, pr: proteins regulation, cp: chaperones, sp: structural proteins, tp: transport proteins). 

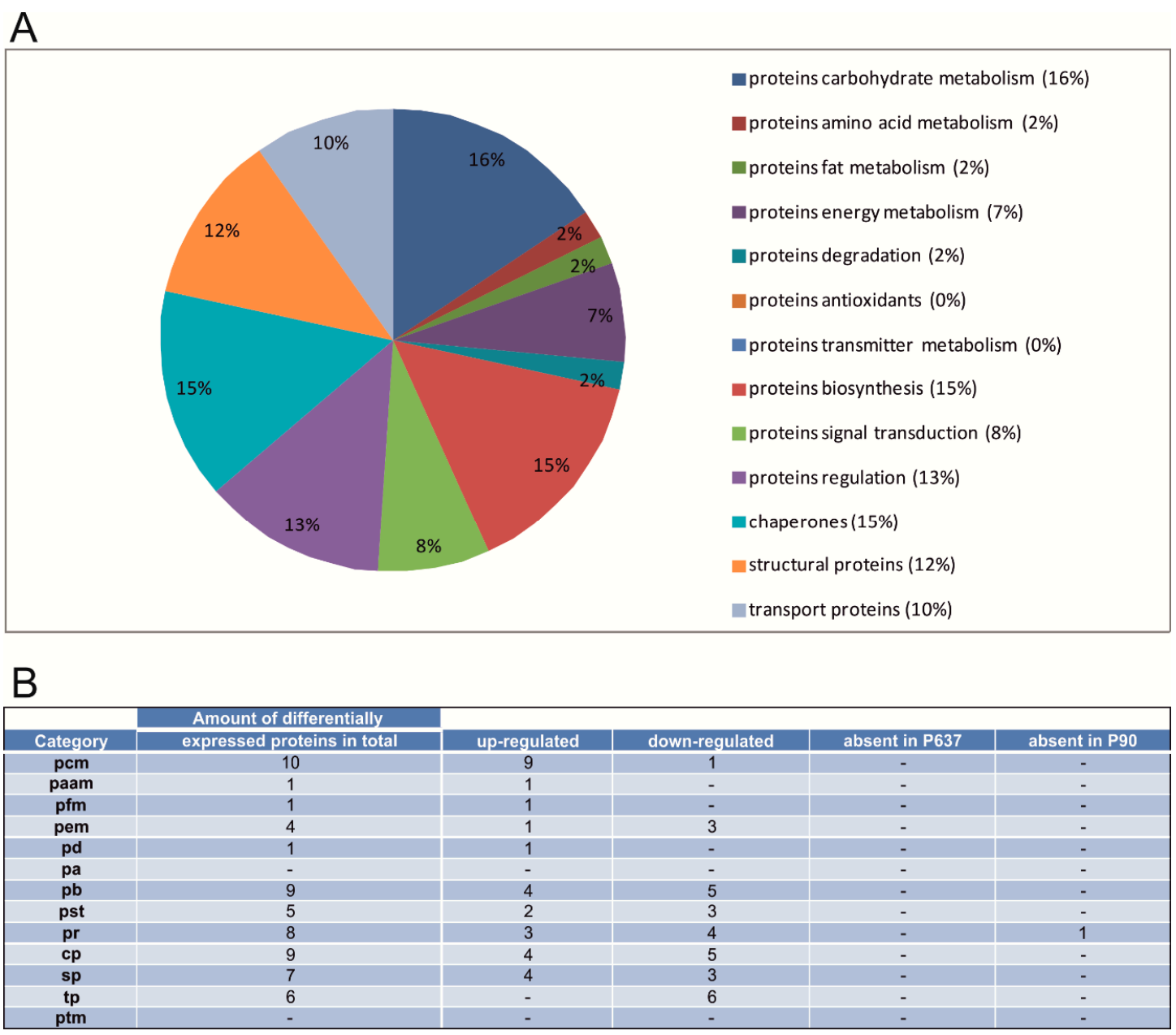

Figure 4. Differential expression of proteins in the Ce at P637. (A) Relative frequencies of proteins in the Ce that are differentially expressed (P637 vs. P90); (B) Number of differentially expressed proteins of different protein categories within the Ce (P637) vs. (P90). Same abbreviations performed as in Figure 3B.

At developmental stage $\mathrm{P} 7$, the proteins involved in biosynthesis sum up to an amount of 23 proteins which are differentially expressed, from which 15 proteins show an up-regulation with respect to their expression in P90. The protein UMP-CMP kinase (Cmpk1) is required for cellular nucleic acid biosynthesis. Another up-regulated protein is aspartate-tRNA ligase (Dars)* which is a part of the multi-enzyme complex of aminoacyl-tRNA synthetases. Furthermore, elongation factor 1-alpha 1 (Eefla1) and elongation factor 1-gamma (Eef1g) also belong to the group of up-regulated proteins at this stage of development. Both of them present subunits of the elongation factor- 1 complex. Altogether, five proteins including the far upstream element-binding protein 1 (Fubp1) with an ATP-dependent DNA helicase function and the transcriptional activator protein Pur-alpha (Pura) are down-regulated at P7. In addition, three proteins are absent at P90 compared to P7 (for example, the protein eukaryotic translation initiation factor 4A1 (Eif4a1)*). Serine/arginine-rich splicing factor 1 (Srsf1)* plays a role in preventing exon skipping, ensuring the accuracy of splicing and regulating alternative splicing. Nuclease-sensitive element-binding protein 1 (Ybx1) mediates pre-mRNA alternative splicing regulation. The 60S acidic ribosomal protein P0 (Rplp0)* catalyzes protein synthesis and is a component of the 60S subunit and the L10P family of ribosomal proteins. 
Ten regulatory proteins are down-regulated when comparing P7 to P90, like the protein adenosinkinase (Adk), for example. The protein tropomodulin-2 (Tmod2) presents a neuronal-specific member of the tropomodulin family of actin-regulatory proteins. Another neuron specific down-regulated protein is hippocalcin-like protein 1 (Hpcal1), a member of the calcium-binding proteins family found in the retina and brain. Also the protein DJ-1 (Park7)*, which acts as a positive regulator of androgen receptor-dependent transcription, shows a down-regulation. Also, 13 proteins altogether are up-regulated towards P90. The protein cofilin-1 (Cfl1), for example, which exhibits pH-sensitive F-actin depolymerizing activity and plays a role in the regulation of cell morphology and cytoskeletal organization. Neuromodulin (Gap43) is another up-regulated protein, typically expressed at high levels in neuronal growth cones during development and axonal regeneration. Tubulin folding cofactor B (Tbcb), another up-regulated protein, has the ability to bind to alpha-tubulin folding intermediates and is also involved in the regulation of tubulin heterodimer dissociation. Thioredoxin (Txn) and thioredoxin-like protein 1 (Txn11) which also show an up-regulation towards P90 are both involved in different redox reactions and in the reversible $S$-nitrosylation of cysteines in certain proteins. An absent protein at this developmental stage, endophilin-B1 (Sh3glb1)* may be involved in regulating apoptotic signaling pathways and maintaining mitochondrial morphology.

The amount of up- and down-regulation of the structural proteins is more or less balanced. Eight proteins are up-regulated at this stage. These proteins are mainly involved in the dynamic organization of the cytoskeleton, like actin-related protein 3 (Actr3), member of the Arp $2 / 3$ complex, dihydropyrimidinase-related protein 3 (Dpys13) or F-actin-capping protein subunit alpha-1 (Capza1), F-actin-capping protein subunit beta (Capzb) and Fascin (Fscn1)*. Other up-regulated proteins are the myristoylated alanine-rich C-kinase substrate (Marcks) which supports the crosslinking of actin filaments. Stathmin (Stmn1) also displays an up-regulation and is involved in the regulation of the microtubule filament system. Twelve proteins are down-regulated towards P90. These are mainly members of the septin family (septin-11 (Sept11), septin-5 (Sept5)*, septin-8 (Sept8)*) that are involved in a variety of cellular functions including cytokinesis and vesicle trafficking. Other down-regulated proteins are for example members of the neurofilament family (neurofilament light polypeptide (Nefl), neurofilament medium polypeptide (Nefm), alpha-internexin (Ina)) which comprise the axoskeleton and functionally maintain the neuronal caliber.

All in all, at developmental stage $\mathrm{P} 7$, a total of 140 proteins is expressed differentially as compared to $\mathrm{P} 90$, of which 63 proteins are up-regulated, 72 proteins are down-regulated and five proteins are absent at P90 (Table 2).

Table 2. Overview of the differential expression of the proteins in P7 vs. P90 as well as P637 vs. P90.

\begin{tabular}{ccc}
\hline \multirow{2}{*}{ Categories } & Amount (P7) & Amount (P637) \\
\cline { 2 - 3 } & \multicolumn{2}{c}{ (Absolute } \\
& 140 & 61 \\
Total & 63 & 30 \\
Up-regulated & 72 & 30 \\
Down-regulated & 0 & 0 \\
Absent & 5 & 1 \\
Absent P90 &
\end{tabular}


For P637 in comparison to P90, differences in the expression are also noticeable. At first, beginning with the functional group with the highest number of differentially expressed members, the proteins of the carbohydrate metabolism, nine proteins are up-regulated and one protein is down-regulated compared to P90. The up-regulated protein faction contains alcohol dehydrogenase (Akrla1)*. This protein also shows an up-regulation at P7 towards P90. Fructose-bisphosphate aldolase $\mathrm{C}^{*}$, a member of the class I fructose-biphosphate aldolase gene family is expressed specifically in the hippocampus and Purkinje cells of the brain. A down-regulation of it can be seen at P7. Dihydrolipoyllysine-residue acetyltransferase component of pyruvate dehydrogenase complex (Dlat) also displays an up-regulation in this developmental stage. The down-regulated protein towards P90 of this category is phosphoglycerate kinase 1 (Pgk1)*. An expression change of it in P7 towards P90 could not be observed.

Four chaperone proteins are up-regulated. These contain two different subunits of the T-complex protein 1 (which has a molecular chaperone function), subunit gamma (Cct3) and epsilon (Cct5). Other up-regulated proteins include the endoplasmic reticulum resident protein 29 (Erp29)* which plays an important role in the processing of secretory proteins within the endoplasmic reticulum. Also the heat shock cognate $71 \mathrm{kDa}$ protein (Hspa8)* is up-regulated at this stage which binds to nascent polypeptides to facilitate correct folding for example. However, also the down-regulated proteins (a total of five proteins) contain different members of the heat shock protein family (heat shock protein Hsp 90-beta (Hsp90ab1), heat shock $70 \mathrm{kDa}$ protein 4 (Hspa4)*, heat shock 70kDa protein 5 (Hspa5). These proteins also show a down-regulation at $\mathrm{P} 7$ towards $\mathrm{P} 90$. Other proteins which are down-regulated are calreticulin (Calr)* and protein disulfide-isomerase A3 (Pdia3). While Calr presents a calcium-binding chaperone, Pdia3 interacts with lectin chaperones calreticulin a calnexin to modulate folding of newly synthesized glycoproteins.

The proteins which are involved in the pathways of the protein biosynthesis consist of four proteins which are up-regulated and five proteins which display a down-regulation at P637. The up-regulated group contains the heterogeneous nuclear ribonucleoprotein $\mathrm{H} 2$ (Hnrnph2), a component of the heterogeneous nuclear ribonucleoprotein complexes. In addition, the delta interacting protein 2 (Poldip2)* also shows an up-regulation at this developmental stage. The group of down-regulated proteins includes for example serine/threonine-protein phosphatase 2A catalytic subunit beta isoform (Ppp2cb) as well as the transcriptional activator protein Pur-alpha (Pura) which plays a role in the initiation of DNA replication and recombination.

At P637, a total amount of 61 proteins are expressed differentially as compared to P90, of which 30 proteins show an up-regulation, 30 proteins show a down-regulation and one protein is absent in P90 (Table 2).

\section{Discussion}

In general, the Ce does not contain a homogeneous cell population. For this reason, a differential proteome analysis includes not only the proteome changes of the neuronal populations, but also the differential expression of proteins from other cell populations in the Ce. The technique of separation used in this study, allows a separation within the range of approximately $10-100 \mathrm{kDa}$ and between a $\mathrm{pH}-$ range of 3-10. Therefore, it is possible to analyze a major part, but not the entire proteome of the Ce [22]. In addition, the external parts of the gel show a lower resolution which presents another possibility for a 
misinterpretation of the regulation analysis of some protein spots. Additionally, it is known that proteins may be compromised in multiple spots within different locations in the gel which can be a reason for different posttranslational modifications and isoforms of the same protein. Therefore, different proteins within a particular spot may show only an average change of the spot volume, but this does not concurrently apply for a specific protein of such a mixture of proteins within the same spot (see Table S1, Figure S2). With the aid of other mass spectrometric detection methods like the stable isotope ratio mass spectrometry (SIRMS), it would be possible to identify both the protein and its variants more precisely and to overcome the sample-to-sample recovery variabilities associated with non-SIRMS MS-proteomic methods. In addition, an improved analysis of the lower expressed and abundant proteins would be allowed by using affinity-enrichment-MS methods and targeted biomarker discovery applications (e.g., IDBEST ${ }^{\mathrm{TM}}$, iTRAQ ${ }^{\mathrm{TM}}$ ) [23]. Therefore, the results of this study dealing with the proteomic analysis of the Ce should be seen as a first step towards getting an overview of the differentially expressed protein patterns in this region of the brain.

This study focuses on the analysis of expression differences in the abundance of proteins and gives an overview of developmental changes in the rat Ce by analyzing snapshots (P7, P90, P637) in the development. Focus is placed on differences in the expression of proteins for neuronal development in the Ce. Changes in the expression of proteins were analyzed and compared with existing findings in the literature. Specific changes of cytoplasmatic proteins of the postnatal developing Ce were found. However, these proteins need to be validated by Western-Blots and/or immunohistochemistry in an ongoing study. Such a verification is also important with regard to some differences in statistically significant and not significant changes of protein expressions by applying the multi condition coverage method and the Mann-Whitney $U$-test.

At the developmental stage P7 in comparison to P90, especially proteins involved in biosynthesis, regulatory proteins and structural proteins showed increased expression changes. At P637, mainly proteins of the carbohydrate metabolism, chaperones and proteins participating in the biosynthetic processes demonstrated the highest amount of differentially expressed proteins. These findings suggest that the above mentioned categories of proteins are important for the development, for example, for the maintenance of the cytoskeleton and the energy metabolism of the rat cerebellum. At P7, the majority of the differentially expressed proteins involved in regulatory processes are down-regulated when compared to P90. Several of the differentially expressed proteins of this category are associated with the regulatory dynamics of the cytoskeleton in the $\mathrm{Ce}$ as well as transmitter release. For example, the protein adenosinkinase (Adk), down-regulated at P7, presents a protein which is involved in three main processes [24]. It has the ability to influence the concentration of cyclic AMP and, therefore, acting as a chemical link between electrical activity and the changes in the intracellular concentration of cyclic AMP [25]. Secondly, it may also be involved in the vasodilatory regulation of cerebral blood flow in arterioles [26,27]. The alteration of the properties of synaptic transmission between parallel fibers and Purkinje cells presents another possible function of this protein [28]. Furthermore, Studer et al. [29] were able to show that in the early development, hippocampal adenosine kinase expression appears mainly in neurons and shifts to glia during the second postnatal week. Another down-regulated protein involved in the organization of the cytoskeleton is tropomodulin-2 (Tmod2). This protein, as mentioned in the results, is responsible for the regulation of actin filaments by capping the pointed ends of an actin filament and together with tropomyosin, stabilizing the filament and regulating its length [30,31]. 
Therefore, actin plays an important role in growth cone motility during development and the pre- and postsynaptic morphology of neurons. Especially Tmod2, also refers to as neuronal Tmod, is the isoform found in neuronal structures. Hippocalcin-like protein 1 (Hpcall) is another protein down-regulated in the early stages of development in the Ce. This protein displays a high homology to hippocalcin which presents a neuron-specific calcium-binding protein, highly expressed in hippocampal pyramidal cells. This protein is able to interact with neuronal apoptosis inhibitory proteins to promote neuronal survival [32]. Its increase in expression in the developing hypothalamus suggests that Hpcall may promote neuronal survival in this region [33]. Other proteins involved in the organization of the cytoskeleton, cofilin-1 (Cfl1) and neuromodulin (Gap43) show both an up-regulated expression compared to P90. While Cfl1 is involved in the regulation of actin cytoskeleton dynamics and cell morphology, Gap43 is responsible for establishing neuronal growth cones formation during development and axonal regeneration. For Cfl1, a higher expression in the early stages of development agrees with the findings of Gurniak et al. [34] in which this protein is essential for the neuronal development in the mouse. For example, the establishment of neural crest cell migration and closure effects of the neural tube is impaired by the deletion of Cfl1 in the mouse. Console-Bram et al. [35] were able to determine that the expression of Gap43 mRNA in cerebellar granule cells and inferior olivary cells during development indicates that this growth-associated protein is initially involved in granule cell differentiation and migration, parallel and climbing fiber axonal outgrowth and synaptogenesis [36]. Also in their study, it could be shown by Northern blot analysis that cerebellar GAP-43 mRNA expression increases from birth to postnatal day 7 and then declines to a lower level in the adult. Especially in the deep cerebellar nuclei the protein was found to be most intense during the first postnatal week. This suggests that GAP-43 may influence Purkinje cell axon and cerebellar nuclear dendritic synaptogenesis as synaptic contact takes place during the first postnatal week [37,38]. The later decrease may indicate completion of axonal outgrowth from the deep cerebellar nuclei [35]. Also other proteins involved in the regulation of the cytoskeleton and neurogenesis show a difference in their expression during the development stages. Tubulin folding cofactor B (Tbcb), also up-regulated at P7, is located in the neurite ends of neuroblasts and in the growth cone transition zone which is essentially responsible for the negative regulation of axonal growth and microtubule dynamics [39]. Endophilin-B1 (Sh3glb1)* is absent at the early development stage of P7. Sh3glb1, a member of the BAR domain protein super-family, is an essential element of cellular traffic. It has a prominent function in synaptic vesicle endocytosis, receptor trafficking and apoptosis, and in other processes that require remodeling of the membrane structure [40]. There are different isoforms of this protein available, for endophilin-B1, this protein has been implicated in many stages of clathrin mediated synaptic vesicle endocytosis, from early events generating membrane curvature, to later stages such as vesicle fission and uncoating [41,42]. Furthermore, a selective depletion of endophilin from rat brain cytosol inhibited the generation of synaptic-like microvesicles and markedly reduced the formation of dynamin-coated tubules on synaptic membranes [41,43].

The majority of proteins involved in the processes of protein biosynthesis display an up-regulation at P7 in comparison to P90. Especially proteins involved in nucleic acid biosynthesis (Cmpk1) and the supply of new synthesized tRNA (Dars*, Eef1a1, Eef1g) are up-regulated. In the mammalian nervous system, transcripts exhibit multiple forms of splicing which presents an important step in growth processes such as axon guidance, synaptogenesis, and the regulation of membrane physiology [44-47]. Furthermore, different members of the family of the heterogeneous nuclear ribonucleoproteins 
(hnRNPs) are partially up- and down- regulated towards P90. While the heterogeneous nuclear ribonucleoprotein K (Hnrnpk)* and heterogeneous nuclear ribonucleoprotein F (Hnrnpf) show a greater expression at P7 compared to P90, other members (heterogeneous nuclear ribonucleoprotein $\mathrm{H} 1$, isoform CRA_b (Hnrph1)*, for example) present a higher expression at later stages (P637) of development. This protein family plays key roles in mRNA metabolism, DNA-related functions and microRNA biogenesis by regulating stability, localization and translation of a number of transcripts which represents an important step in the establishment and maintenance of nerve cell functions [48-52]. The regulation of the expression of many RNAs depends on the activity of RNA-binding proteins, often acting in concert and organized in complexes, probably regulating the activity and the expression of the other components of the complex itself [53]. The different expression levels of these members could indicate they are involved in different tasks and during development. For example, Hnrnpk* is also involved in other cellular processes, such as modulation, translation mRNA transport and signal transduction [54,55]. As Proepper et al. [56] were able to demonstrate Hnrnpk, plays an important role during neuronal differentiation and early synapse formation by interacting with other proteins which are important for dendritic branching and synapse formation (Abelson-interacting protein 1 (Abi-1), for example).

As mentioned in the results, the amount of structural proteins shows a balanced amount of up- and down-regulated proteins in the analyzed developmental stages. Especially proteins for the dynamic organization of the cytoskeleton are up-regulated at the stage of P7. For example, different subunits of the F-actin-capping protein (F-actin-capping protein subunit alpha-1 (Capza1), F-actin-capping protein subunit beta (Capzb)) and additional proteins, important for the functional formation of actin and the cytoskeleton are up-regulated at this stage (stathmin (Stmn1), myristoylated alanine-rich C-kinase substrate (Marcks)). As Devaux et al. [57] stated, the ability to dynamically organize parts of the cytoskeleton can support neuronal differentiation, including axonal growth, branching and dendritic development. Therefore, an up-regulation of these proteins appears to be an important step for the cytoskeletal organization in the $\mathrm{Ce}$. Further structural proteins are members of the neurofilament family (neurofilament light polypeptide (Nefl), neurofilament medium polypeptide (Nefm)) which are functionally related to axonal growth, neuronal polarity and signaling in axon guidance [58] are down-regulated at P7 in comparison to P90. As mentioned by Riederer et al. [59], in the Ce, changes in the expression and distribution of the neurofilament proteins appear during maturation differentially for different cell types. For example, in the Ce of kittens, while afferent mossy and climbing fibers in the medullary layer contained NF-M and NF-L already at birth, other cell types show a different expression of these proteins. Within the first three postnatal weeks, for example, all three subunits appeared in mossy and climbing fibers in the internal granular and molecular layers and in the axons of Purkinje cells. Axons of local circuit neurons such as basket cells expressed these proteins at the end of the first month, whereas parallel fibers expressed them last, at the beginning of the third postnatal month. Also different members of the septin-protein family are down-regulated at P7. Also these proteins seem to have an important role in the developing brain by being integrated in microcircuits, including the dendritic arborization and the synthesis of dendritic spines. While septin 5 (Sept5)* is localized in the presynaptic terminals and frequently associated with synaptic vesicles [60-62], septin 11 (Sept11) also plays a role in GABAergic synaptic connectivity, particularly within the postsynapse, and concentrates at the neck of dendritic spines in the intact brain [63]. A differential protein expression was also 
observable in aged rat brains (P637). The main differences in the expression concern the categories of proteins of the carbohydrate metabolism, proteins of the biosynthesis and chaperones.

The proteins which are functionally integrated in the glucose metabolism clearly demonstrate a high amount of up-regulated proteins towards P90. As described in the results, except for one protein (phosphoglycerate kinase $\left.1(\operatorname{Pgk} 1)^{*}\right)$, all other proteins show an up-regulation in expression at this developmental stage. Several of these proteins are involved in the utilization of glucose by being integrated or associated in the tricarboxylic cycle (e.g., dihydrolipoyllysine-residue acetyltransferase component of pyruvate dehydrogenase complex (Dlat)). Also Vannucci R.C. and Vannucci S.J. [64] were able to demonstrate that the utilization of glucose to maintain tissue energy stores is increased in the newborn rat brain. However, the glucose transport capacity and simultaneously the rate of glucose uptake of the immature brain are much lower than in the adult animal. Under normoxic conditions, glucose uptake into newborn rat brain proceeds at one-fifth the rate it does in adult brain [65]. Furthermore, it is known that with increasing age, a decrement of the cerebellar glucose metabolic rate can be observed which also reflects significant impairments in several cognitive tasks for example. An additional increase in the expression of proteins which are involved in the glucose metabolism between the adult age (P90) and aged rats (P637) in our study could, therefore, be an indicator for the reaction of the animal to the decreasing metabolic rate to maintain a physiological state of glucose metabolism conditions and to supply energy for neuronal integrity for example.

The proteins involved in different tasks of protein biosynthesis belong to the group which displays the second highest rate of differentially expressed proteins in the Ce of aged rats compared to adult animals. Here, the amount of up- and down-regulated proteins is balanced at this stage. As mentioned in the results, the protein heterogeneous nuclear ribonucleoprotein $\mathrm{H} 2$ (Hnrnph2) is one of the members of the up-regulated group, a protein important for serving as a crucial checkpoint in pre-mRNA processing [66]. In general, members of this protein family (heterogeneous nuclear ribonucleoprotein complex) are involved in mRNA metabolism, DNA-related functions and microRNA biogenesis, including processing in alternative splicing during neuronal differentiation [48]. These proteins include a diverse group of proteins containing RNA binding motifs as well as several auxiliary domains. Therefore, a simultaneous binding of pre-mRNA and other proteins is possible [67]. As Meshorer et al. [66] describes in his work, a misregulation of these proteins by aging can influence splice site selection or lead to alternative or aberrant splicing of different downstream target sequences which then can lead to uncontrolled cell proliferation or to different age-related diseases (Age-related macular degeneration, Alzheimer's disease, etc.). As stated by Tollervey et al. [68], especially genes with metabolic functions show expression changes during aging which are linked with alternative splicing. This indicates that alternative splicing complements the transcriptional regulation in modifying the molecular machinery for the repair of oxidative DNA damage in the brain [69]. The group of down-regulated proteins contains the protein serine/threonine-protein phosphatase $2 \mathrm{~A}$ catalytic subunit beta isoform (Ppp2cb). As described in the results, this protein is responsible for regulating the negative control of cell growth and division, for example. As mentioned by Price and Mumby [70], protein phosphatase 2A can also have unique functions in neuronal cells. Within neurons, PP2A seems to be targeted to specific intracellular locations, such as neurofilaments by probably controlling stability and interactions with other components of the neuronal cytoskeleton [71]. This indicates that at this developmental stage, also the amount of expressed neurofilaments should decrease. At least in our study a change of expression between P90 and 
P637 was not observable. However, Vega et al. [72] were able to show that in old rats a significant decrease in the density of neurofilament light polypeptide immnoreactivity occurs, suggesting that cytoskeletal abnormalities are also present within physiological aging.

Moreover, the category of chaperones also displays an amount of proteins which have a differential expression in the analyzed developmental stages. The up-regulated proteins consist of two different subunits of the T-complex protein 1, subunit gamma (Cct3) and epsilon (Cct5) members of the chaperonin containing TCP1 complex. Actin and tubulin are consistently found in the TCP-1 complex favoring the idea that they are its major substrates $[73,74]$. The up-regulation of these proteins could be an indication of increasing stress induced by aging and possibly a misregulation of the cytoskeletal portion in the Ce. As described by Proctor et al. [75], neurodegeneration is an age-related disorder which is characterized by the accumulation of aggregated protein, loss of protein homeostasis and neuronal cell death. The capacity of chaperones is sufficient to maintain protein homeostasis. Even under conditions of increasing stress with age, normal chaperone capacity is able to process the increasing overload due to the mechanism of up-regulation of chaperones after stress. Though other chaperones (heat shock protein Hsp 90-beta (Hsp90ab1), heat shock $70 \mathrm{kDa}$ protein 4 (Hspa4)*, heat shock $70 \mathrm{kDa}$ protein 5 (Hspa5)) show a down-regulated expression at this stage. As stated by Soerensen and Leoschke [76], a possible theory for the decreased expression of these proteins could be an adaptive down-regulation of the energetically expensive Hsp-system to conserve energy for other purposes, directly causing the decrease in stress resistance with age. Another reason for the decreased expression of proteins with chaperone and folding functions could indicate a loss of protein quality regulation with aging that may contribute to the buildup of cytoskeletal proteins (e.g., increased neurofilament light chain and tubulin) with increasing age [77].

In addition, it could be determined that other differentially expressed proteins of the analyzed developmental stages are involved in proliferation, migration and differentiation. For example, proteins participating in transport processes, additional proteins involved in the carbohydrate metabolism and proteins involved in the energy homeostasis of the brain indicate additional important protein categories for the development of the Ce. Also Becker et al. [78] were able to find regional differences in the Ce proteome in comparison to the inferior colliculus, for example. In this study, especially Proteins involved in energy metabolism including proteins participating in glycolysis, intracellular signaling cascades and vesicle trafficking showed main differences in expression. Others [79] were able to identify changes in the protein expression in brains of different ages. Also here, they were able to provide evidence for the differential regulation of specific proteins which are important for several metabolic pathways including regulatory proteins.

Further investigation is needed, but some of these proteins could present important factors for the differentiation and survival of transplanted progenitor cells in neonatal and adult striata. In additional studies, this could also open up the possibility to associate the differential expressed proteins to their specific metabolic pathways and to determine the factors which are important for the differentiation of neuronal progenitor cells. Furthermore, in the brains of adult (P90) and aged rats (P637) a differential expression was also detectable. This indicates that in the adult $\mathrm{Ce}$, there are still remodeling processes for different categories of proteins possible ongoing which could play a role in cell replacement by aging, learning and memory as well as synaptic signaling and messaging. This also offers the option to analyze 
and separate proteins to determine factors which show an importance in the protein expression, for other major cerebellar disorders like NPC1 for example, in future studies.

\section{Experimental Section}

\subsection{Treatment}

Male Wistar rats (Rattus norvegicus, Charles River, Sulzfeld, Germany) of different ages (7, 90, 637 postnatal days) with six animals in each group were used for this study [80,81]. The animals were housed at $22 \pm 2{ }^{\circ} \mathrm{C}$ under an artificial day and night rhythm with a $12 \mathrm{~h}$ light-dark cycle with free access to water and standard nutrition. The animal treatment and experimental procedures were conducted in compliance with the regulations and licensing of the local authorities (Landesamt für Landwirtschaft, Lebensmittelsicherheit and Fischerei Mecklenburg Vorpommern, Germany) and the Animal Care and Use Committee of the University of Rostock. According to the European Communities Council Directive of 24 November 1986 (86/609/EEC) and in accordance with the above-mentioned local authorities adequate measures were taken to minimize pain or discomfort.

\subsection{Perfusion and Dissection}

At defined dates (7, 90, 637 days postnatal), perfusion was performed. The animals were anesthetized with ether and killed by intraperitoneal Pentobarbital- $\mathrm{Na}^{+}$-injection $(60 \mathrm{mg} / \mathrm{kg} \mathrm{BW})$. Transcardial perfusion was performed with $100-400 \mathrm{~mL}$ (bodyweight depending) cooled $\left(4{ }^{\circ} \mathrm{C}\right) 0.9 \% \mathrm{NaCl}$-solution. After decapitation and brain dissection, the dissected brain regions were weighed and stored at $-80{ }^{\circ} \mathrm{C}$ until homogenization. From pentobarbital injection to $-80^{\circ} \mathrm{C}$ storage it took less than $5 \mathrm{~min}$.

\subsection{Homogenization}

The extraction of proteins was performed according to published standardized protocols [82-84]. Each developmental stage (P7, P90, P637) consisted of six gel images. For P7, P90 and P637, each gel image presents a single dissected brain region. The brain sections were incubated with $(9 \times$ probe mass (mg)) $\mu \mathrm{L}$ lysis buffer consisting of $7 \mathrm{M}$ urea (Sigma, Steinheim, Germany), $2 \mathrm{M}$ thiourea (Sigma), 4\% CHAPS (Sigma), 70 mM DTT (Sigma), 0.5\% Bio-Lyte Ampholytes pH 3-10 (Fluka, Buchs, Switzerland) and a mixture of protease inhibitors (Roche, Basel, Switzerland) additionally enriched with $(0.1 \times$ probe mass $(\mathrm{mg})) \mu \mathrm{L}$ Pepstatin A and PMSF (Fluka) and snap-frozen at $-150{ }^{\circ} \mathrm{C}$. The samples were quickly thawed and transferred into a $2 \mathrm{~mL}$ Wheaton potter (neo-lab, Heidelberg, Germany) for homogenization. In the next step, glass beads (Roth, Karlsruhe, Germany) were added to the suspension, following a $15 \mathrm{~s}$ sonication, $15 \mathrm{~s}$ vortexing (repeated six times) and finished by shock freezing the suspension at $150{ }^{\circ} \mathrm{C}$. After quickly thawing the samples, they were put in a beaker on a magnetic stirrer that was filled with ice water for $15 \mathrm{~min}$. Finally, the samples were centrifuged at $17,860 \times \mathrm{g}$ for $20 \mathrm{~min}$ at $4{ }^{\circ} \mathrm{C}$. The supernatant was very carefully removed using a $2 \mathrm{~mL}$ syringe (Becton Dickinson, Heidelberg, Germany) with a $0.5 \times 25 \mathrm{~mm}$ needle (Becton Dickinson), because of a thick lipid coverage derived from myelinated nerve fibers. The protein concentration of the supernatant was determined by the Bradford assay. 


\subsection{Two Dimensional Polyacrylamide Gel Electrophoresis (2DE)}

\subsubsection{Rehydration}

The first dimension was performed in a PROTEAN IEF cell system (Bio-Rad, Berkeley, CA, USA). Protein extracts of $1 \mathrm{mg}$ protein were loaded on immobilized $\mathrm{pH}$ 3-10 nonlinear gradient strips with a length of $17 \mathrm{~cm}$ (GE-Healthcare, Buckinghamshire, UK; Art.: 17-1235-01) and actively rehydrated with $300 \mu \mathrm{L}$ rehydration buffer consisting of $6 \mathrm{M}$ urea (Sigma), $2 \mathrm{M}$ thiourea (Sigma), 2\% CHAPS (Sigma), $16 \mathrm{mM}$ DTT (Sigma), 0.5\% Bio-Lyte Ampholytes pH 3-10 (Fluka) at $50 \mathrm{~V}$ for $12 \mathrm{~h}$ at $20^{\circ} \mathrm{C}$.

\subsubsection{First Dimension: Isoelectric Focusing}

After rehydration, to reduce artifacts, electrode wicks (Bio-Rad) were added. Focusing started with the "conditioning step" ( $2 \mathrm{~h}$ ) which subdivides in two sub-steps: (a) linear voltage rise to $500 \mathrm{~V}$, step-hold $30 \mathrm{~min}$; (b) linear voltage rise to $2500 \mathrm{~V}$, step-hold $1 \mathrm{~h}$. After that, the "slow voltage ramping" $(2.5 \mathrm{~h})$ : quadratic voltage rise to $8000 \mathrm{~V}$ and the "final focusing": actual process of focusing (duration: 50.000 Vhrs) were performed. During the whole IEF the temperature was constantly kept at $20{ }^{\circ} \mathrm{C}$. After focusing the strips were stored at $-80{ }^{\circ} \mathrm{C}$.

\subsubsection{Second Dimension: Polyacrylamide Gel Electrophoresis}

Focused IPG-strips were equilibrated in two steps of $30 \mathrm{~min}$ each in $5 \mathrm{~mL}$ of freshly prepared SDS equilibration solution consisting of $1.5 \mathrm{M}$ Tris- $\mathrm{HCl} \mathrm{pH} 8.8$ (Roth), $6 \mathrm{M}$ urea (Sigma), 30\% glycerol (Sigma), 2\% SDS (Sigma), trace of bromophenol blue (Roth) supplemented with $10 \mathrm{mg} / \mathrm{mL}$ DTT and $40 \mathrm{mg} / \mathrm{mL}$ iodoacetamide.

The strips were transferred on $12 \%$ homogeneous self-cast sodium dodecyl sulfate polyacrylamide gels $(200 \mathrm{~mm} \times 250 \mathrm{~mm} \times 1.5 \mathrm{~mm})$. At $125 \mathrm{~V}$ per gel (Power Pac 1000, Bio-Rad), they were run in the PROTEAN Plus Dodeca Cell (Bio-Rad). To ensure a constant buffer-temperature of $10{ }^{\circ} \mathrm{C}$, a cooling device (Julabo F10, Julabo Labortechnik, Seelbach, Germany) was used.

\subsubsection{Fixation and Staining}

Fixation was performed with acetic acid-methanol solution (45\% methanol, $1 \%$ acetic acid overnight. Staining of the gels was performed in a colloidal CBB G250 solution ( $1 \mathrm{~g} / 1000 \mathrm{~mL})$ (Roth) as described previously [85]. After $24 \mathrm{~h}$, the gels were destained with ultrapure water and were held in cold storage $\left(4{ }^{\circ} \mathrm{C}\right)$ with ultrapure water until digitization.

\subsection{Gel Analysis}

\subsubsection{Digitization}

The stained gels $(n=6)$ were scanned as 12 bit gray scale tif-images with a F4100 scanner (Heidelberg, Heidelberg, Germany) at 300 dpi resolution. Gels were rinsed in $0.02 \%$ sodium azide (Aldrich Chemie, Steinheim, Germany), shrink-wrapped in plastic and stored at $4{ }^{\circ} \mathrm{C}$ until picking for MALDI-TOF-MS. 


\subsubsection{Digital Gel Processing}

For 2DE-gel image analysis, the software package Progenesis PG200 Version 2006 (Nonlinear Dynamics Ltd., Newcastle upon Tyne, UK) was used. The gels were registered to a reference gel (the gel which contained most spots with highest separation and staining quality and least artifacts) and manually edited spots were matched to allow comparability of all gels (Figure 1).

\subsubsection{Determination of Differentially Abundant Protein Spots}

Protein spots in 2DE were quantified by normalizing spot volumes using the Progenesis PG200 (Nonlinear Dynamics Ltd., Newcastle upon Tyne, UK) and spot volume differences were calculated. After the comparison of the normalized gray value-spot volumes of all generated spot pairs with Access and Excel (Windows, Microsoft Corporation, Redmond, WA, USA), the comparison of the spot volumes was determined by calculation of the spot volume quotient (SVQ, P90/P7 or P90/P637). Only those spots were considered to be significantly up- or down-regulated that showed a SVQ (Spot Volume Quotient) of 0.6 or less and 1.67 or greater $[83,84,86]$. The differences were evaluated significantly if differentially expressed spots were detected in at least four gel images (correlated spots) belonging to one test group. Instead of applying a parametric or non-parametric statistical test, the multi condition coverage method was used with condition 1: change of SVQ $<0.67$ or SVQ $>1.67$ and condition 2: changes in four of six gels. In addition the nonparametric Mann-Whitney $U$-test was applied. If multiple spots of one protein were detected by mass spectrometric analysis, the differential expression was determined by the mean of their individual expression levels. Additionally, each protein which exists in a mixed spot with at least another protein in one developmental stage was marked individually as well as if one protein was present in multiple spots per stage (see Table S1). The classification of the differentially expressed proteins in their respective functional protein groups itself was generated by a comparison of the proteins' properties; in addition, the basic function of each protein is briefly described (according to Entrez Gene, GeneCards, UniProtKB/Swiss-Prot, and/or UniProtKB/TrEMBL).

\subsubsection{Mass Spectrometric Analysis of Protein Spots}

According to published standardized protocols [87], protein spots were excised from the gels with a spot picker (Flexys Proteomics picker, Genomic Solutions, Ann Arbor, MI, USA), transferred into 96-well plates, and subjected to in-gel digestion with trypsin. The gel plugs were washed twice with $30 \%$ acetonitrile (ACN) in $25 \mathrm{mM}$ ammonium bicarbonate and $50 \% \mathrm{ACN}$ in $10 \mathrm{mM}$ ammonium bicarbonate, respectively, shrunk with ACN, and dried at $37{ }^{\circ} \mathrm{C}$. The dried gel plugs were re-swollen with $5 \mu \mathrm{L}$ protease solution (sequencing grade trypsin, $10 \mathrm{ng} / \mu \mathrm{L}$ in $3 \mathrm{mM}$ Tris- $\mathrm{HCl}, \mathrm{pH} 8.5$, Promega, Madison, WI, USA) and incubated for $8 \mathrm{~h}$ at $37{ }^{\circ} \mathrm{C}$. Thereafter, $5 \mu \mathrm{L}$ of extraction solution $(0.3 \%$ trifluoroacetic acid, 50\% ACN) were added and the samples were agitated at room temperature for 30-60 min before the peptide extracts were transferred into the 96-well collection plates. The resulting peptide-containing solution was prepared for MALDI analysis by spotting $0.6 \mu \mathrm{L}$ of the tryptic digest and $0.45 \mu \mathrm{L}$ of matrix solution consisting of $9 \mathrm{mg} / \mathrm{mL} \alpha$-cyano-4-hydroxy-cinnamic acid (CHCA) in $50 \%$ ACN, 0.1\% trifluoroacetic acid on standard stainless steel MALDI plates. MALDI-MS analysis was performed on a 4700 Proteomics Analyzer MALDI-TOF/TOF mass spectrometer (Applied 
Biosystems, Foster City, CA, USA). All acquired spectra were processed using 4700 Explore $^{\mathrm{TM}}$ software (Applied Biosystems, Warrington, Cheshire, UK). For protein identification, spectra were submitted to MASCOT (version 2.4.0, Matrix Science, London, UK) via the MASCOT Deamon. Searches were performed against the subset of rat proteins of the UniProtKB protein sequence database (2012_01; 42755 sequences from Rattus). A mass tolerance of $60 \mathrm{ppm}$ and one missing cleavage site were set, oxidation of methionine residues was considered as variable modification, and carbamidomethylation of cysteines as fixed modification. Peptide masses of trypsin autoproteolysis products and matrix-derived peaks were excluded. Identifications with Mascot scores greater than 59 were considered significant $(p<0.05)$. All results were examined carefully for reliability and occurrence of multiple proteins in the same sample.

\section{Conclusions}

In conclusion, the proteomic analysis of the Ce at three different developmental stages displays multiple changes in the expression of proteins. This includes a down- and up-regulation of single proteins and the occurrence of single proteins which are only present at specific developmental stages. Although the analysis of the differential 2D gels spot abundance does not exclude the simultaneous presence of proteins/isoforms with no detectable abundance differences. As mentioned in the results, the presence of abundance of single proteins could also result from different posttranslational modifications. However, the main focus of this study was to detect differences in the abundance of single protein spots to provide indications of developmental changes in protein expression during the development (P7, P90, P637) of the cerebellum and not in the characterization of structural differences of one protein in different spots, for example. As a further step, in an analysis of single protein candidates, all individual spots belonging to the protein have to be detected and its differential regulation has to be identified, including spots which show a lower resolution in the gel. Therefore, increasing the system's sensibility and reproducibility by using additional methods (e.g., difference gel electrophoresis, DIGE), as well as the application of purification protocols could provide a more detailed view on small proteins (e.g., neurotransmitters, plasma membrane proteins) for further analysis. Another option would be an enhancement of the SVQ ranges $(>1.67,<0.6)$ and the analysis of additional postnatal dates to give more insight in the development of the rat Ce. Though, an overview in the analysis of developmental protein expression changes in the Ce at the postnatal days of P7, P90 and P637 could be evaluated in this study.

\section{Supplementary Materials}

Supplementary materials can be found at http://www.mdpi.com/1422-0067/16/09/21454/s1.

\section{Acknowledgments}

We appreciate the outstanding work of Stefan Mikkat by identifying the proteins with the technique of MALDI-TOF-MS. 


\section{Author Contributions}

Michael Wille carried out the spot segmentation and drafted the manuscript. Antje Schümann carried out the two-dimensional polyacrylamide gel electrophoresis. Grit Mutzbauer optimized two-dimensional polyacrylamide gel electrophoresis for brain tissue. Michael Kreutzer participated in the database management of the spot lists and performed the picking of spots. Michael O. Glocker, Andreas Wree and Oliver Schmitt participated in the design of the study. Oliver Schmitt performed the dissection of the material and the sample preparation. Oliver Schmitt conceived of the study, and participated in its design and coordination and helped to draft the manuscript. All authors read and approved the final manuscript.

\section{Conflicts of Interest}

The authors declare no conflict interest.

\section{Abbreviations}

A, Axon; CBB, Coomassie blue; Cpg, Cytoplasmic granule; Cts, Centrosome; Cr, Chromosome; Csk, Cytoskeleton; cp, Chaperones; Cpm, Cytoplasm; Cpv, Cytoplasmic vesicle; Cts, Cytosol; ER, Endoplasmic reticulum; Eds, Endosome; Exr, Extracellular region; Gc, Growth cone; Gj, Gap junction; Golgi, Golgi apparatus; hGc, Heterotrimeric G-protein complex; La, Lipid-anchor; Lyso, Lysosome; M, Membrane; Micro, Microsome; Mmt, Mitochondrial matrix; Mm, Mitochondrial membrane; Mim, Mitochondrion inner membrane; MimS, Mitochondrion intermembrane space; Mom, Mitochondrion outer membrane; Mel, Melanosome; Mito, Mitochondrion; MT, Microtubule; Nc, Nucleus; Nf, Neurofilament; Nm, Nucleus matrix; Np, Nucleoplasm; P, Proteasome; pa, Proteins antioxidants; paam, Proteins amino acid metabolism; pb, Proteins biosynthesis; pcm, Proteins carbohydrate metabolism; pd, Proteins degradation; Per, Peroxisome; pem, Proteins energy metabolism; Pema, Proteinaceous extracellular matrix; pfm, Proteins fat metabolism; PMp, Peripheral Membrane protein; pr, Proteins regulation; pst, Proteins signal transduction; ptm, Proteins transmitter metabolism; Rs, Ribosome; S, Synapse; Sc, Secreted; Scc, Spliceosomal complex; sER, Smooth endoplasmic reticulum; sp, Structural proteins; Sv, Synaptic vesicle; Ss, Synaptosome; SR, Sarcoplasmic reticulum; TCA, Trichloroacetic acid; tp, Transport proteins; Ulc, Ubiquitin ligase complex.

\section{References}

1. Ghez, C.; Fahn, S. The cerebellum. In Principles of Neural Science; Kandel, E.R., Schwartz, J.H., Eds.; Elsevier: New York, NY, USA, 1985.

2. Wu, T.; Hallett, M. The cerebellum in Parkinson's disease and parkinsonism in cerebellar disorders. Brain 2013, 136, doi:10.1093/brain/awt089.

3. Benabid, A.L.; Pollak, P.; Gervason, C.; Hoffmann, D.; Hommel, M.; Perret, J.E.; de Rougemont, J.; Gao, D.M. Long-term suppression of tremor by chronic stimulation of the ventral intermediate thalamic nucleus. Lancet 1991, 337, 403-406. 
4. Payoux, P.; Remy, P.; Damier, P.; Miloudi, M.; Loubinoux, I.; Pidoux, B.; Gaura, V.; Rascol, O.; Samson, Y.; Agid, Y. Subthalamic nucleus stimulation reduces abnormal motor cortical overactivity in Parkinson disease. Arch. Neurol. 2004, 61, 1307-1313.

5. Ganser, C.; Papazoglou, A.; Just, L.; Nikkhah, G. Neuroprotective effects of erythropoietin on 6-hydroxydopamine-treated ventral mesencephalic dopamine-rich cultures. Exp. Cell Res. 2010, 316, 737-746.

6. Hovakimyan, M.; Haas, S.J.; Schmitt, O.; Gerber, B.; Wree, A.; Andressen, C. Mesencephalic human neural progenitor cells transplanted into the neonatal hemiparkinsonian rat striatum differentiate into neurons and improve motor behaviour. J. Anat. 2006, 209, 721-732.

7. Haas, S.J.; Petrov, S.; Kronenberg, G.; Schmitt, O.; Wree, A. Orthotopic transplantation of immortalized mesencephalic progenitors (CSM14.1 cells) into the substantia nigra of hemiparkinsonian rats induces neuronal differentiation and motoric improvement. J. Anat. 2008, 212, 19-30.

8. Cologna, S.M.; Jiang, X.S.; Backlund, P.S.; Cluzeau, C.V.; Dail, M.K.; Yanjanin, N.M.; Siebel, S.; Toth, C.L.; Jun, H.S.; Wassif, C.A.; et al. Quantitative proteomic analysis of Niemann-Pick disease, type $\mathrm{C} 1$ cerebellum identifies protein biomarkers and provides pathological insight. PLoS ONE 2012, 7, e47845.

9. Bray, D.; Gilbert, D. Cytoskeletal elements in neurons. Annu. Rev. Neurosci. 1981, 4, 505-523.

10. Burgoyne, R.D. Microtubule proteins in neuronal differentiation. Comp. Biochem. Physiol. B 1986, $83,1-8$.

11. Burgoyne, R.D.; Cumming, R. Characterisation of microtubule-associated proteins at the synapse: Absence of MAP 2. Eur. J. Cell Biol. 1983, 30, 154-158.

12. Weeds, A. Actin-binding proteins-regulators of cell architecture and motility. Nature 1982, 296, 811-816.

13. Hirn, M.; Ghandour, M.S.; Deagostini-Bazin, H.; Goridis, C. Molecular heterogeneity and structural evolution during cerebellar ontogeny detected by monoclonal antibody of the mouse cell surface antigen BSP-2. Brain Res. 1983, 265, 87-100.

14. Bunge, M.B. The axonal cytoskeleton: It's role in generating and maintaining cell form. Trends Neurosci. 1986, 9, 477-482.

15. Dustin, P. Microtubules, 2nd ed.; Springer-Verlag: Berlin, Germany, 1984.

16. Burgoyne, R.D.; Cambray-Deakin, M.A.; Norman, K.M. Developmental regulation of tyrosine kinase substrate p36 (calpactin heavy chain) in rat cerebellum. J. Mol. Neurosci. 1989, 1, 47-54.

17. Adlard, B.P.; Dobbing, J. Phosphofructokinase and fumarate hydratase in developing rat brain. J. Neurochem. 1971, 18, 1299-1303.

18. Teichgräber, P.; Biesold, D. Properties of membrane-bound hexokinase in rat brain. J. Neurochem. 1968, 15, 979-989.

19. Hamburgh, M; Flexner, L.B. Biochemical and physiological differentiation during morphogenesis-XXI. J. Neurochem. 1957, 1, 279-288.

20. De Vellis, J.; Schjeide, O.A.; Clemente, C.D. Protein synthesis and enzymic patterns in the developing brain following head x-irradiation of newborn rats. J. Neurochem. 1967, 14, 499-511.

21. Leong, S.F.; Clark, J.B. Regional development of glutamate dehydrogenase in the rat brain. J. Neurochem. 1984, 43, 106-111. 
22. Becker, M.; Schindler, J.; Nothwang, H.G. Neuroproteomics - the tasks lying ahead. Electrophoresis 2006, 27, 2819-2829.

23. Schneider, L.V.; Hall, M.P. Stable isotope methods for high-precision proteomics. Drug Discov. Today 2005, 10, 353-363.

24. Phillips, E.; Newsholme, E.A. Maximum activities, properties and distribution of 5'nucleotidase, adenosine kinase and adenosine deaminase in rat and human brain. J. Neurochem. 1979, 33, 553-558.

25. Newman, M.; McIlwain, H. Adenosine as a constituent of the brain and of isolated cerebral tissues, and its relationship to the generation of adenosine $3^{\prime}: 5^{\prime}$-cyclic monophosphate. Biochem. J. 1977, 164, 131-137.

26. Berne, R.M.; Rubio, R.; Curnish, R.R. Effect on cerebral vascular resistance and incorporation into cerebral adenine nucleotides. Circ. Res. 1974, 35, 262-271.

27. Rubio, R.; Berne, R.M.; Bockman, E.L.; Curnish, R.R. Relationship between adenosine concentration and oxygen supply in rat brain. Am. J. Physiol. 1975, 228, 1896-1902.

28. Atterbury, A.; Wall, M.J. Adenosine signalling at immature parallel fibre-Purkinje cell synapses in rat cerebellum. J. Physiol. 2009, 587, 4497-4508.

29. Studer, F.E.; Fedele, D.E.; Marowsky, A.; Schwerdel, C.; Wernli, K.; Vogt, K.; Fritschy, J.M.; Boison, D. Shift of adenosine kinase expression from neurons to astrocytes during postnatal development suggests dual functionality of the enzyme. Neuroscience 2006, 142, 125-137.

30. Kong, K.Y.; Kedes, L. Leucine 135 of tropomodulin-1 regulates its association with tropomyosin, its cellular localization, and the integrity of sarcomeres. J. Biol. Chem. 2006, 281, 9589-9599.

31. Kostyukova, A.S.; Rapp, B.A.; Choy, A.; Greenfield, N.J.; Hitchcock-De Gregori, S.E. Structural requirements of tropomodulin for tropomyosin binding and actin filament capping. Biochemistry 2005, 44, 4905-4910.

32. Mercer, E.A.; Korhonen, L.; Skoglösa, Y.; Olsson, P.A.; Kukkonen, J.P.; Lindholm, D. NAIP interacts with hippocalcin and protects neurons against calcium-induced cell death through caspase-3-dependent and -independent pathways. EMBO J. 2000, 19, 3597-3607.

33. Stead, J.D.; Neal, C.; Meng, F.; Wang, Y.; Evans, S.; Vazquez, D.M.; Watson, S.J.; Akil, H. Transcriptional profiling of the developing rat brain reveals that the most dramatic regional differentiation in gene expression occurs postpartum. J. Neurosci. 2006, 26, 345-353.

34. Gurniak, C.B.; Perlas, E.; Witke, W. The actin depolymerizing factor n-cofilin is essential for neural tube morphogenesis and neural crest cell migration. Dev. Biol. 2005, 278, 231-241.

35. Console-Bram, L.M.; Fitzpatrick-McElligott, S.G.; McElligott, J.G. Distribution of GAP-43 mRNA in the immature and adult cerebellum: A role for GAP-43 in cerebellar development and neuroplasticity. Dev. Brain Res. 1996, 95, 97-106.

36. Benowitz, L.I.; Apostolides, P.J.; Perrone-Bizzozero, N.; Finklestein, S.P.; Zwiers, H. Anatomical distribution of the growth-associated protein GAP-43/B-50 in the adult rat brain. J. Neurosci. 1988, 8, 339-352.

37. Altman, J.; Bayer, S.A. Prenatal development of the cerebellar system in the rat. II. Cytogenesis and histogenesis of the inferior olive, pontine gray, and the precerebellar reticular nuclei. J. Comp. Neurol. 1978, 179, 49-75. 
38. Gardette, R.; Debono, M.; Dupont, J.L.; Crepel, F. Electrophysiological studies on the postnatal development of intracerebellar nuclei neurons in rat cerebellar slices maintained in vitro Postsynaptic potentials. Brain Res. 1985, 351, 47-55.

39. Lopez-Fanarraga, M.; Carranza, G.; Bellido, J.; Kortazar, D.; Villegas, J.C.; Zabala, J.C. Tubulin cofactor B plays a role in the neuronal growth cone. J. Neurochem. 2007, 100, 1680-1687.

40. Kjaerulff, O.; Brodin, L.; Jung, A. The structure and function of endophilin proteins. Cell Biochem. Biophys. 2011, 60, 137-154.

41. Ringstad, N.; Gad, H.; Löw, P.; di Paolo, G.; Brodin, L.; Shupliakov, O.; de Camilli, P. Endophilin/SH3p4 is required for the transition from early to late stages in clathrin-mediated synaptic vesicle endocytosis. Neuron 1999, 24, 143-154.

42. Gad, H.; Ringstad, N.; Löw, P.; Kjaerulff, O.; Gustafsson, J.; Wenk, M.; di Paolo, G.; Nemoto, Y.; Crun, J.; Ellisman, M.H.; et.al. Fission and uncoating of synaptic clathrin-coated vesicles are perturbed by disruption of interactions with the SH3 domain of endophilin. Neuron 2000, 27, 301-312.

43. Schmidt, A.; Wolde, M.; Thiele, C.; Fest, W.; Kratzin, H.; Podtelejnikov, A.V.; Witke, W.; Huttner, W.B.; Söling, H.D. Endophilin I mediates synaptic vesicle formation by transfer of arachidonate to lysophosphatidic acid. Nature 1999, 401, 133-141.

44. Wilbur, D.O.; Patel, M.S. Development of mitochondrial pyruvate metabolism in rat brain. J. Neurochem. 1974, 22, 709-715.

45. Black, D.L.; Grabowski, P.J. Alternative pre-mRNA splicing and neuronal function. Prog. Mol. Subcell. Biol. 2003, 31, 187-216.

46. Lipscombe, D. Neuronal proteins custom designed by alternative splicing. Curr. Opin. Neurobiol. 2005, 15, 358-363.

47. Ule, J.; Darnell, R.B. RNA binding proteins and the regulation of neuronal synaptic plasticity. Curr. Opin. Neurobiol. 2006, 16, 102-110.

48. Cao, W.; Razanau, A.; Feng, D.; Lobo, V.G.; Xie, J. Control of alternative splicing by forskolin through hnRNP K during neuronal differentiation. Nucleic Acids Res. 2012, 40, 8059-8071.

49. Kuhl, D.; Skehel, P. Dendritic localization of mRNAs. Curr. Opin. Neurobiol. 1998, 8, 600-606.

50. Derrigo, M.; Cestelli, A.; Savettieri, G.; di Liegro, I. RNA-protein interactions in the control of stability and localization of messenger RNA (review). Int. J. Mol. Med. 2000, 5, 111-123.

51. Roegiers, F.; Jan, Y.N. Staufen: A common component of mRNA transport in oocytes and neurons? Trends Cell Biol. 2000, 10, 220-224.

52. Raimondi, L.; Cannino, G.; D’Asaro, M.; Sala, A.; Savettieri, G.; di Liegro, I. Regulation of RNA metabolism in the nervous system. Recent Res. Dev. Neurochem. 2002, 5, 39-48.

53. Keene, J.D.; Tenenbaum, S.A. Eukaryotic mRNPs may represent posttranscriptional operons. Mol. Cell. 2002, 9, 1161-1167.

54. Bomsztyk, K.; van Seuningen, I.; Suzuki, H.; Denisenko, O.; Ostrowski, J. Diverse molecular interactions of the hnRNP K protein. FEBS Lett. 1997, 403, 113-115.

55. Bomsztyk, K.; Denisenko, O.; Ostrowski, J. hnRNP K: One protein multiple processes. Bioessays 2004, 26, 629-638.

56. Proepper, C.; Steinestel, K.; Schmeisser, M.J.; Heinrich, J.; Steinestel, J.; Bockmann, J.; Liebau, S.; Boeckers, T.M. Heterogeneous nuclear ribonucleoprotein k interacts with Abi-1 at postsynaptic sites and modulates dendritic spine morphology. PLOS ONE 2011, 6, e27045. 
57. Devaux, S.; Poulain, F.E.; Devignot, V.; Lachkar, S.; Irinopoulou, T.; Sobel, A. Specific serine-proline phosphorylation and glycogen synthase kinase $3 \beta$-directed subcellular targeting of stathmin 3/Sclip in neurons. J. Biol. Chem. 2012, 287, 22341-22353.

58. Maurya, D.K.; Sundaram, C.S.; Bhargava, P. Proteome profile of the mature rat olfactory bulb. Proteomics 2009, 9, 2593-2599.

59. Riederer, B.M.; Porchet, R.; Marugg, R.A. Differential expression and modification of neurofilament triplet proteins during cat cerebellar development. J. Comp. Neurol. 1996, 364, 704-717.

60. Kinoshita, A.; Noda, M.; Kinoshita, M. Differential localization of septins in the mouse brain. J. Comp. Neurol. 2000, 428, 223-239.

61. Xue, J.; Tsang, C.W.; Gai, W.P.; Malladi, C.S.; Trimble, W.S.; Rostas, J.A.; Robinson, P.J. Septin 3 (G-septin) is a developmentally regulated phosphoprotein enriched in presynaptic nerve terminals. J. Neurochem. 2004, 91, 579-590.

62. Takamori, S.; Holt, M.; Stenius, K.; Lemke, E.A.; Grønborg, M.; Riedel, D.; Urlaub, H.; Schenck, S.; Brügger, B.; Ringler, P.; et.al. Molecular anatomy of a trafficking organelle. Cell 2006, 127, 831-846.

63. Li, X.; Serwanski, D.R.; Miralles, C.P.; Nagata, K.; de Blas, A.L. Septin 11 is present in GABAergic synapses and plays a functional role in the cytoarchitecture of neurons and GABAergic synaptic connectivity. J. Biol. Chem. 2009, 284, 17253-17265.

64. Vannucci, R.C.; Vannucci, S.J. Glucose metabolism in the developing brain. Semin. Perinatol. 2000, 24, 107-115.

65. Vannucci R.C.; Christensen, M.A.; Stein, D.T. Regional cerebral glucose utilization in the immature rat: Effect of hypoxia-ischemia. Pediatr. Res. 1989, 26, 208-214.

66. Meshorer, E.; Soreq, H. Pre-mRNA splicing modulations in senescence. Aging Cell 2002, 1, 10-16.

67. Krecic, A.M.; Swanson, M.S. hnRNP complexes: Composition, structure, and function. Curr. Opin. Cell Biol. 1999, 11, 363-371.

68. Tollervey, J.R.; Wang, Z.; Hortobágyi, T.; Witten, J.T.; Zarnack, K.; Kayikci, M.; Clark, T.A.; Schweitzer, A.C.; Rot, G.; Curk, T. Analysis of alternative splicing associated with aging and neurodegeneration in the human brain. Genome Res. 2011, 21, 1572-1582.

69. Lu, T.; Pan, Y.; Kao, S.Y.; Li, C.; Kohane, I.; Chan, J.; Yankner, B.A. Gene regulation and DNA damage in the ageing human brain. Nature 2004, 429, 883-891.

70. Price, N.E.; Wadzinski, B.; Mumby, M.C. An anchoring factor targets protein phosphatase 2A to brain microtubules. Mol. Brain Res. 1999, 73, 68-77.

71. Janssens, V.; Goris, J. Protein phosphatase 2A: A highly regulated family of serine/threonine phosphatases implicated in cell growth and signalling. Biochem. J. 2001, 353, 417-439.

72. Vega, J.A.; del Valle, M.; Amenta, F. Expression of neurofilament proteins in the rat cerebellar cortex as a function of age: An immunohistochemical study. Mech. Ageing Dev. 1994, 73, 9-16.

73. Yaffe, M.B.; Farr, G.W.; Miklos, D.; Horwich, A.L.; Sternlicht, M.L.; Sternlicht, H. TCP1 complex is a molecular chaperone in tubulin biogenesis. Nature 1992, 358, 245-248.

74. Sternlicht, H.; Farr, G.W.; Sternlicht, M.L.; Driscoll, J.K.; Willison, K.; Yaffe, M.B. The t-complex polypeptide 1 complex is a chaperonin for tubulin and actin in vivo. Proc. Natl. Acad. Sci. USA 1993, 90, 9422-9426. 
75. Proctor, C.J.; Lorimer, I.A. Modelling the role of the Hsp70/Hsp90 system in the maintenance of protein homeostasis. PLOS ONE 2011, 6, e22038.

76. Soerensen, J.G.; Loeschke, V. Decreased heat-shock resistance and down-regulation of Hsp70 expression with increasing age in adult Drosophila melanogaster. Funct. Ecol. 2002, 16, 379-384.

77. Vanguilder, H.D.; Freeman, W.M. The hippocampal neuroproteome with aging and cognitive decline: Past progress and future directions. Front. Aging Neurosci. 2011, 8, doi:10.3389/fnagi.2011.00008

78. Becker, M.; Nothwang, H.G.; Friauf, E. Different protein profiles in inferior colliculus and cerebellum: A comparative proteomic study. Neuroscience 2008, 154, 233-244.

79. Chen, W.; Ji, J.; Xu, X.; He, S.; Ru, B. Proteomic comparison between human young and old brains by two-dimensional gel electrophoresis and identification of proteins. Int. J. Dev. Neurosci. 2003, 21, 209-216.

80. International Genetic Standardization (IGS) Program. Available online: www.criver.com/files/ $\mathrm{pdfs} / \mathrm{rms} / \mathrm{rm} \_$rm_r_igs.aspx (accessed on 4 June 2015).

81. Pass, D.; Freeth, G. The Rat. Anzccart News 1993, 6, 1-4.

82. Klose, J.; Kobalz, U. Two-dimensional electrophoresis of proteins: An updated protocol and implications for a functional analysis of the genome. Electrophoresis 1995, 16, 1034-1059.

83. Wille, M.; Schümann, A.; Kreutzer, M.; Glocker, M.O.; Wree, A.; Mutzbauer, G.; Schmitt, O. The proteome profiles of the olfactory bulb of juvenile, adult and aged rats - an ontogenetic study. Proteome Sci. 2015, 13, 1-17.

84. Lessner, G.; Schmitt, O.; Haas, S.J.; Mikkat, S.; Kreutzer, M.; Wree, A.; Glocker, M.O. Differential proteome of the striatum from hemiparkinsonian rats displays vivid structural remodeling processes. Proteome Res. 2010, 9, 4671-4687.

85. Lorenz, P.; Bantscheff, M.; Ibrahim, S.M.; Thiesen, H.J.; Glocker, M.O. Proteome analysis of diseased joints from mice suffering from collagen-induced arthritis. Clin. Chem. Lab. Med. 2003, 41, 1622-1632.

86. Röwer ,C.; Koy, C.; Hecker, M.; Reimer, T.; Gerber, B.; Thiesen, H.J.; Glocker, M.O. Mass spectrometric characterization of protein structure details refines the proteome signature for invasive ductal breast carcinoma. J. Am. Soc. Mass Spectrom. 2011, 22, 440-456.

87. Konus M.; Koy, C.; Mikkat, S.; Kreutzer, M.; Zimmermann, R.; Iscan, M.; Glocker, M.O. Molecular adaptations of Helicoverpa armigera midgut tissue under pyrethroid insecticide stress characterized by differential proteome analysis and enzyme activity assays. Genom. Proteom. 2013, 8, 152-162.

88. Paxinos, G. The Rat Nervous System, 3nd ed; Academic Press: London, UK, 2004.

89. Bandeira, F.; Lent, R.; Herculano-Houzel, S. Changing numbers of neuronal and non-neuronal cells underlie postnatal brain growth in the rat. Proc. Natl. Acad. Sci. USA 2009, 106, 14108-14113.

90. Cayre, M.; Canoll, P.; Goldman, J.E. Cell migration in the normal and pathological postnatal mammalian brain. Prog. Neurobiol. 2009, 88, 41-63.

91. Bhattacharya, B.; Saha, S.; Sarkar, P.K. Post-transcriptional regulation of tubulin mRNA in developing rat brain. Brain Res. Mol. 1991, 10, 347-350.

92. Migheli, A.; Piva, R.; Casolino, S.; Atzori, C.; Dlouhy, S.R.; Ghetti, B. A cell cycle alteration precedes apoptosis of granule cell precursors in the weaver mouse cerebellum. Am. J. Pathol. 1999, $155,365-373$. 
93. The BrainTx Committee NIJC. Cerebellar Development Transcriptome Database. 2014. Available online: http://www.cdtdb.neuroinf.jp/CDT/Download.do (accessed on 1 April 2015).

94. Altman, J. Morphological development of the rat cerebellum and some of its mechanisms. Exp. Brain Res. 1982, 6, 8-49.

95. Faivre-Sarrailh, C.; Lena, J.Y.; Had, L.; Vignes, M.; Lindberg, U. Location of profilin at presynaptic sites in the cerebellar cortex; implication for the regulation of the actin-polymerization state during axonal elongation and synaptogenesis. J. Neurocytol. 1993, 12, 1060-1072.

96. Altman, J. Postnatal development of the cerebellar cortex in the rat. II. Phases in the maturation of Purkinje cells and of the molecular layer. J. Comp. Neural. 1972, 145, 399-464.

97. Altman, J. Coated vesicles and synaptogenesis. A developmental study in the cerebellar cortex of the rat. Brain Res. 1971, 30, 311-322.

98. Stone, T.W. Glutamate as the neurotransmitter of cerebellar granule cells in the rat: Electrophysiological evidence. Br. J. Pharmacol. 1979, 66, 291-296.

99. Altman, J.; Bayer, S.A. Development of the cerebellar system in relation to its Evolution, Structure and Functions; CRC Press: New York, NY, USA, 1997.

100. Mason, C.A.; Gregory, E. Postnatal maturation of cerebellar mossy and climbing fibers: Transient expression of dual features on single axons. J. Neurosci. 1984, 4, 1715-1735.

101. Bertoni-Freddari, C.: Giuli, C.; Pieri, C.; Paci, D. Age-related morphological rearrangements of synaptic junctions in the rat cerebellum and hippocampus. Arch. Gerontol. Geriatr. 1986, 5, 297-304.

(C) 2015 by the authors; licensee MDPI, Basel, Switzerland. This article is an open access article distributed under the terms and conditions of the Creative Commons Attribution license (http://creativecommons.org/licenses/by/4.0/). 